ARGONNE NATIONAL LABORATORL

9700 South Cass Avenue

Argonne, L1linois 60439

NEUTRONIC ANALYSIS OF THE THREE NLL ISLAND

UNIT 2 EX-CJRE DETECTÓR RESIONSE

by

D. J. Malloy and I'. l. Charg

Applied Physics Divisiun

Technical Contributors

C. H. Adams

E. K. Fujita

E. M. Gelbard

L. J. Milton

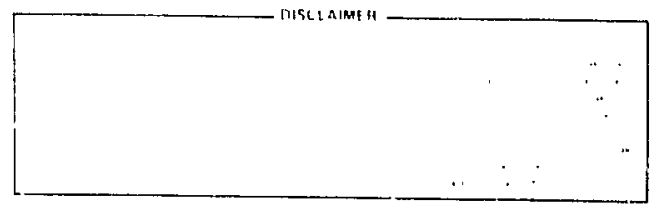

October 1981

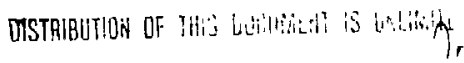


AbSTKA.". . . . . . . . . . . . . . . . . . . . 1

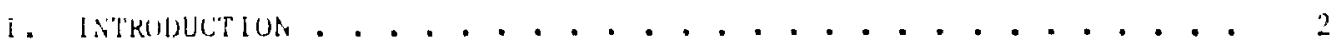

A. Callinlational Mellodubopy . . . . . . . . . . . 2

b. Sorsece Detiation . . . . . . . . . . . . . . . . 1

C.. Callulatiomal Yodel . . . . . . . . . . . . . . 5

11. KLSULl's . . . . . . . . . . . . . . . . . . 4

A. Homoleneuus Voiding bltecls . . . . . . . . . . . . 8

B. Inhomogenenus Voiding protiles............. 10

1. Mode: 1 - 40\% Maximum Void Up to Boil-oft lnterface,

$100 \%$ Void Above . . . . . . . . . . . . . . 11

2. Model 2 - $30 \%$ Maximum Void Up to Boil-of 1 Incerface, $95 \%$ Void Above................... 14

3. Model 3-40\% Maximum Void llp te Boll-oft Interface, $95 \%$ Void Above, Axially Distributed Pholoneutron Source Utilized ................ 16

C. Intermediate Range Detector Response............ IH

D. Impact of Downcomer Bypass Region and Released Source In bowncomer.................... 19

1. Effect of a Split Downcomer Region .......... 19

2. Effect of a Hypothetical Distributed Source Within the Duwncomer................ 19

III. SuMMAKY . . . . . . . . . . . . . . . . 22

A. Period of Approximate Homogeneous Voiding ( 0 to 1 hour

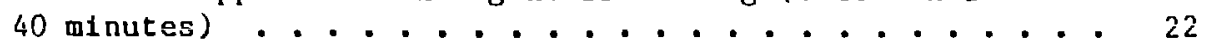

B. Period of Inhomogeneous Voiding and Coolant Lev $\geq 1$ Irregularities ( $>1$ hour 40 minutes) ......... 23

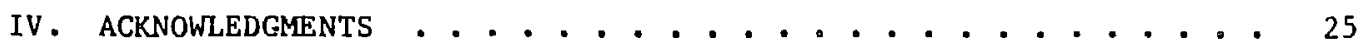

V. REFERENCES .......................... 26

APPENDIX A. CALCULATIONAL MODEL MATERIAL DESCRIPTION $\ldots . . . . . .27$ 


\section{LIST OF FIGUKES}

No.

Title

Page

1. Estimate of Photoneutron Emission Rate Following SCRAM . . . . . 5

2. Geometry of TMI-2 Reactor out to the biological shield . . . . o

3. Calculational R\% Model Geometry of TMI-2 Reactor out to the Biological Shield..................... . . 7

4. Expanded Details of the Source Range betectur Area . . . . . . 7

5. Eigenvalue vs. Homogeneous Vold fraction . . . . . . . . . . 9

6. Detectur Absorptions vs. Honogeneous Vuid fraction . . . . . . lll

7. Transmission Probability vs. Homogeneuus Void fraction . . . . lo

8. Model I Detector Absorptions vs. Water Level . . . . . . . 12

9. Model 2 Detector Absorptions vs. Water Level . . . . . . . . . 14

10. Detector Absorptions vs. Wet Core/Downcomer Water Level Differential . . . . . . . . . . . . . . . . . . . . 1

11. Axial Power Distribution In TMI-2 Center Assembly . . . . . . 17

I2. Model 3 Jetector Absurptions vg. Water Level . . . . . . . . 18

13. Split Downcomer Region - Detector Absorptions vs. Water Level . 20

14. Eiffect of a Hypothetical Source Within Donncomer - Detector Absorptions vs. Waler Level . . . . . . . . . . . . . . 21

15. Ex-Vessel Source Range Detector Response: $0+4$ hours . . . . 22

$A^{-1}$. Calculational RZ Model Geometry of TMI-2 Reactor out to the Biological Shield................... 28

A-2. Expanded Detalls of the Source Range Detector Area . . . . . . 28 
I. Neutron Sources Following SCRAM . . . . . . . . . . . . 5

II. Homogeneous Vold Results . . . . . . . . . . . . . . . 9

I!I. Monte Carlo Benchmark of Transport Theory Solution . . . . . 13

IV. TMI-2 Axial Power Distribucton - Centerline Fuel Arsembly... . Ib

V. Axially Dependent Photoneutron Source Density for the Calculational Model . . . . . . . . . . . . . . . 18

A-1. Region Descrintion: TMI-2 RZ Calculational Model . : . . . . 27

A-2. Trace Nuclide Keplacement Scheme ............ 29

A-3. Calculational Model Composition of Reactor Vessel stet! . . . . 29

A-4. Homogenized Number Densities: TMI-2 RZ Calculational Model . . 30 
NEUTRONIC ANALYSIS OF THE THREE MILE ISLAND

UNITT 2 EX-CORE DETECTOR RESPONSE

D. J. Malloy and Y. I. Chang

\section{Tecintcal Contributors}

C. H. Adams

E. K. Fujita

E. M. Gelbard

L. J. Milton

ABS:'RACT

A neutrcnic analysis has been made with respect to the ex-core neutron detector response during the TMI-2 incideut. A series of transport theory calculations quantified the impact upon the detector count rate of various core and downcomer conditions. In particular, various combinations of coolant void content and spatial distributions were investigated to yield the resulting transmission of the photoneutron source to the detector. The impact of a hypothetical distributed source within the downcomer region was also examined in order to simulate the potential effect of the release of neutron producing fission products into the coolant. These results are then offered as potential explanations for the anomalous behavior of the detector during the period of $\sim 20$ minutes through $\sim 3$ hours folluwing the reactor scram. 


\section{I . INTRODUCTION}

The Three Mile Island Unit 2 (TMI-2) reactor experienced an accident. on March 28, 1979 which can most easily be described as a small break LOCA (loss of coolant accident). To summarize the now faniliar accident sequence in a brief manner, the inadvertent loss of steam generator feedwater inftiated a turbine trip and subsequent reactor scram. The continued addition of energy (via decay heat) into a system which had essentlally lost its heat sink, led to primary coolant overpressurizatioll. A rellef value opened, properly, in order to vent the excess steam and depressurize the primary loop. This valve failed in the open position - thus the small break LOCA. Further events in the short term, In particular operator actions, did not significantly alter the fact that the system would continue to depressurize and lose great amounts of the coolant inventory through the falled valve. The result was core uncovery for a short period of time, along with time dependent voiding and varying water level conditions, specifically within the core and downcomer. A more detailed accounting of the accident progression can be found in Refs. $1-3$.

During this time period the ex-core source range neutron detector was exhibiting anomalous count rate behavior. Conjecture following the accident was that one possible explanation for the detector's response would be the changing coolant conditions in the downcomer and core regions. With this hypothesis in mind, a series of neutronic calculations was performed in order to quantify the effects of vartous potential coolant configurations. The interplay of the downcomer water condicions (which acts primarily as a sinield to the detector) and the core coolant state (which deternines the photoneutron source and the neutron multiplication factor) will identify those configurations which can lead to significant abnormalities in the detector response.

This report summarizes the work concerning this subject which occurred during a briet period in late sumer of 1979. At that point in time, a very small data base existed from which useful conclusions could be drawn. Due to the nature of the accident and the obvious public concern, timely results were of the essence. As such, total consistency amongst all of the items addressed in the results section of this report was not practical. For example, mid-way through the analysis a modeling improvement was made. Rather than recreating a consistent set of results which incorporated this improvement, its effect was quantified, acknowledged and the progression of calculations continued with the base model now being the improved varsion. Time constraints precluded any other approach. The impact, however, is not detrimental either to the determination of global trends or the isolation of those conditions which would prorluce the most significant detector effects.

\section{A. Calculational Methodology}

The TMI-2 reactor was modeled in the radial direction out to, and including a portion of, the concrete biojogical shield. The source range detector is located upon the inner surface of this biological shield at the axial midpoint of the artive core. Inasmuch as axial effects are of secondary importance, the model included only a homogenized region of upper and lower internals to act as buffering zones above and below the active core. A vacuum boundary condition was applied to these external boundaries: its 
effect upon a more exact solution of the detector response is negligible. Due to the presence of a large air space between the reactor vessel and the detector, it was necessary to utilize a transport theory solution, specifically via the DIF $3 D^{4}$ code. In view of the fact that large portions of the ex-core structures are modeled, this RZ mockup has much larger memory and running time requirements than for the more typical core only calculations. In particular, a $100 \times 90$ mesh interval grid was necessary in order to mitigate substantial raj effects and, more importantly, mesh spacing induced instabilities. Thus with running time constraints in mind, the transport theory solution utilized only an $\mathrm{S}_{4} \mathrm{P}_{0}$ approximation. Additionally, the energy range group structure was limited to two groups.

The use of a two-group cross section set was not significantly detrimental to the purposes at this work. Some degree of accuracy is lost of course, however, in an LWK environment; it is relatively minor. Mureover, the source range detector is a $B F_{3}$ proportional counter - its response depends upon the thermal neutron induced $B(O)(n, \alpha) L^{\prime}$ reaction which occurs ten times more often than all other reactions combined. The impact of errors in the fast and resonance range of the neutron flux solution is therefore minimized.

The two-group cross section set (thermal cutoff at $1.855 \mathrm{eV}$ ) was created via pin-cell calculations with EPRI-CELL. 5 Isotopic cross sections were generated for each of 5 distinct void fraction levels (i.e. $0.0,0.2,0.4$, (..7 and 1.0) in order to facilj.tate rure accurate calculations of the partially voided portions of the core. During the first $\sim 2.8$ hours of the accident, there was only a small potential for significant core material movement. Therefore, a nominal intact geometry pin cell calculation is generally accurate during the the initial phase of the accident, especially until about 2.8 hours after the reactor scram. After this time, the core is hypothesized to be partially intact and partially damaged in some unspecified geometry; however, a regeneration of cross sections to model this departure from nominal geometry was not attempted in this study.

The neutronics model within DIF3D is one of homogenized regions: each distinct core region of interest is 2 homogenizacion of fuel, clad and coolant. The calculation, however, retains a pin cell quality due to the spatial and energy self-shielding characteristics which are inherent to the microscopic cross sections via the EPRI-CELL generation. As a result, the homogenized DIF3D run is an adequate approximation to an explicit whole core pin cell calculation. This procedure was benchmarked against both the TMI-2 FSAR and ANL PDQ? runs and shown to be quite accurate in reproducing global effects - those effects wirch will determine the detector response to abnormalities within the iore art downcomer.

\section{B. Source Definition}

Following the successful scram of the TMI-2 core, there remains several low magnitudie neutron sources which will be multiplied, diffuse, and eventually create responses within the source range detector. These sources are identified and quantified for inclusion within the transport calculations.

Spcntaneous fission occurs in, primarily, the built up inventory of $240 \mathrm{Pu}$ and $242 \mathrm{Cm}$. The invertory is quite smali, however, due to the fact that the indent occurred at approximately only 50 effective full power days of 
operation after the initial loading. This source, as calculated via the ORIGEN code ${ }^{6}$ (point depletion, buildup and decay), amounts to only $\sim 5.4 \times$ $10^{\mathrm{b}} \mathrm{n} / \mathrm{sec}$-core.

A second neutron source results from the interaction of alpha particles with oxygen: $10_{0}+\alpha+2 !_{N e}+n$. Several isotopes undergo $\alpha$-decay: $>98 \%$ of the $\alpha$ emissions in TMI-2 occur in $238 \mathrm{Pu}, 239 \mathrm{Pu}$ and $240 \mathrm{Pu}$. The resulting total neutron source from $\alpha-n$ reactions is $\sim 1.22 \times 1 U^{7} \mathrm{n} / \mathrm{sec}-$ core.

There are two discrete startup sources in the TMI-2 core: they are reported to be standard $\mathrm{Am}-\mathrm{Cm}-\mathrm{Be}$ type with an initial strength of $1.4 \mathrm{x}$ $1 U^{9} \mathrm{n} / \mathrm{sec}$ apiece. At the time of the accident, the strengths are down to $\sim 10^{y} \mathrm{n} / \mathrm{sec}$ each (

A majur source during the short term is the decay of the full power flux level and delayed neutrons. At shutdown, the average total flux level is $\sim 2.8 \times 10^{14} \mathrm{n} / \mathrm{cm}^{2}-\mathrm{sec}$. Using a 6 -group point kinctics approximation and a very conservative value for the shutdown $k_{\text {eff }}(0.98$ as opposed to the nominal value of 0.92 ), the full power flux level and delayed neutron level falls to about $1000 \mathrm{n} / \mathrm{cm}^{2}-\mathrm{sec}$ in 30 minutes. [For comparison, on external source of $2 \times 10^{9} \mathrm{n} / \mathrm{sec}$ will produce a flux level on the order of $\sim 10^{5} \mathrm{n} / \mathrm{cm}^{2}-\sec ($ Ref. 8 ) l. Several minutes later, this value is totally negligible. This source, therefore, is of little consequence during the time frame of interest.

The last neutron source of any consequence is that from photoneutrons. Gamma interaction with the trace amount of deuterium in the coolant ( $D / H=$ 0.v0015) leads to an $D(\gamma, n) H$ reacticn. Due to the massive amount of $\mathrm{H}_{2}{ }^{()}$ present, this trace reaction produces a sizable neitron surce. One estimate based upon order of magnitude as sumptions $\mathrm{fr}_{i} 1$ hour after SCRAM is $10^{10} \mathrm{n} / \mathrm{sec}$ (Ref. 7). A more accurate estimate was made by combining the explicit $\gamma$ emission spectrum and rate from an ORIGEN calculation with the physical constants of the system: D fraction in $\mathrm{H}_{2} \mathrm{O}$; fraction of released $\gamma^{\prime}$ 's which are ausorbed in $\mathrm{H}_{2} \mathrm{O}(12.6 \%$, see $\operatorname{Ref} .9)$, the $(\gamma, n)$ cross section for $D$, etc. The result is the time dependent photoneutron emission curve depicted in Fig. 1. In this case, the estimate at 1 hour after scram is $\sim 10^{11} \mathrm{n} /$ sec. As can be seeñ, there is a considerable time variation during the period of interest: from $1 / 2$ hour to 3 hours the photoneutron emission rate decreases by a factor of 4.5 .

To summarize the neutron source definition, it appears that all sources are negligible with respect to the photoneutron and start-up sources. Between these two, the photoneutron source dominates for about the first 12 hours after the scram. Subsequent decay of the $Y$ emitters then leads to the start-up source providing a "base level" below which the neutron source will not fall. A numerical summary is provided below in Table $I$.

It should be emphasized at this point that the precise value of the photoneutron source is of secondary importance when compared to establishing the time variation and the order of magnitude estimate for the source. In the first place, it was necessary to identify the dominate neutron source within the system: Table I clearly displays that the photoneutron source is the controlling neutron source during the short term. Secondly, the rime variation of this source indicates that it will dominate for several hours. 


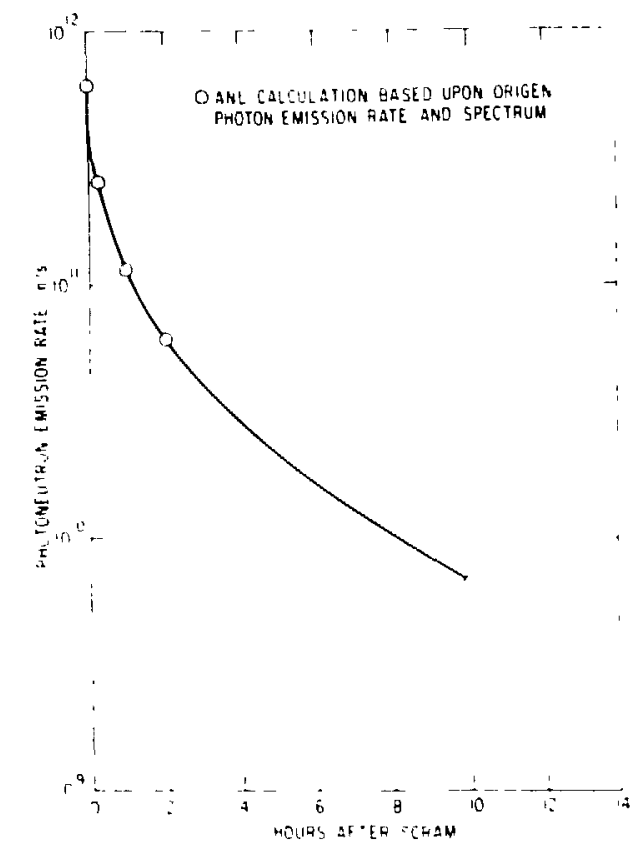

Fig. 1

Estimate of Photoneutron Emission Rate Following SCRAM

TABLE I. Neutron Sources Following SCRAM

\begin{tabular}{lll}
\multicolumn{1}{c}{ Source } & \multicolumn{1}{c}{ n/sec } & Comments \\
\hline Fhotoneutron & $2 \times 10^{11}+4 \times 10^{10}$ & $(1 / 2$ hour to 3 hours) \\
Start-up & $2 \times 10^{9}$ & (Constant with Tilae) \\
Delayed Neutrons & Negligible after 30 minutes \\
$\alpha-n$ & $1.2 \times 10^{7}$ & ( Constant during first 10 hours) \\
Spontaneous Fission & $5.4 \times 10^{6}$ & ( Constant during first 10 hours)
\end{tabular}

Therefore, the analysis concerning the first few hours after the scram can be based upon this source alone. Further, the exact count rate of the detector is never inferred from this analysis, rather the relative change in the number of detector absorptions is utilized. Thus, the impact of the exact magnitude of photoneutron source is minimized. As a consequence, a more precise estimate of the source is not required.

\section{Calculational Mode1}

The simplified geometrical and material layout of the TMI-2 calculational model is described in this section. It is essentially identical to 
t'ie standardized model utilized by the Nuclear Safety Analysis Center (opera-ed by the Electric Power Research Institute) during 1979. An R2 map and dimenions are provided in this section. The more detailed number density and volume fraction infurmation is presented in Appendix $A$. In order to put the following into perspective, a scale drawing of the near core structures is provided in Fig. 2 .

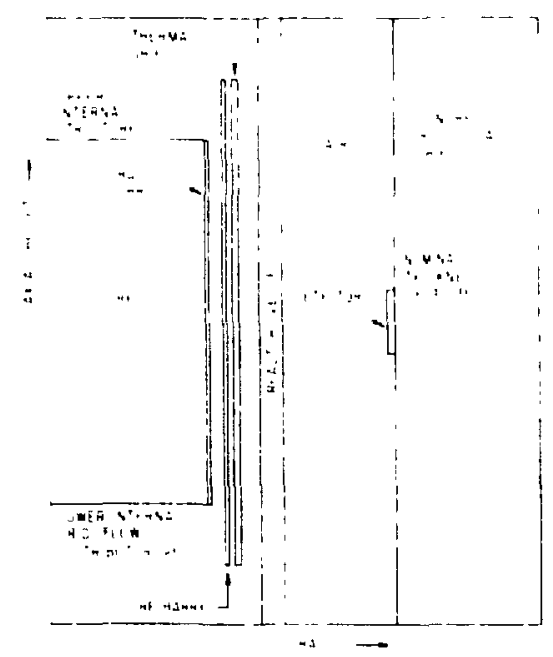

Fig. 2

Geometry of IMI-2 Reactor lut to the Biological shield

As mentioned previously, the core zones are a homogenization of fuel, clad and coslant. More globally, this homogenization extends throughout the core to include each of the 3 distinct biches of fuel: the result is a core material with an average initial enrichment of 2.57 wt. $\% 23 \mathrm{~S}_{\mathrm{U}}$. In anticipation of the introduction of a spatial void distribution, the core ' divided axially into 5 zones. The 12 foot high core has a 1 fout layer of upper internals above and a similar 1 foot layer of lower internals below. In both cases, the internals are represented by an appropriate mixture of coolant and steel.

Adjacent to the core is a downcomer region which extends the entire axial length of the model. This region is a homogenization of the cor barrel, water gaps, thermal shield, core liner and the downcomer regfon proper. It, like the ctre, is divided into axial zones in order to tacilitate spatial studies. This region $1 \mathrm{~s} \sim 74 \%$ water and $\sim 26 \%$ stalnless steel, its width is approximately $53 \mathrm{~cm}(\angle 1 \mathrm{1}$...). The reactor vessel is next, consisting of carbon steel and being $\sim 21 \mathrm{~cm}$ thick $(8-3 / 8 \mathrm{in.}$.). These two regions alone account for the bulk of the shielding of the source range detector from core neutrons.

The biological concrete shield surrounds the reactor vessel at a distance of $112 \mathrm{~cm}(3.8 \mathrm{feet})$. Its nominal thickness is $4.5 \mathrm{feet}$, however, or.ly several mean-free paths of material is modeled in order to provide a zufficient boundry condition. Upon this shield is the source range detector. 
Figure 3 illustrates the full R2 calculational layout with appropriate dimensions; also, a cetailed expansion of the detector area is depicted in Fig. 4.

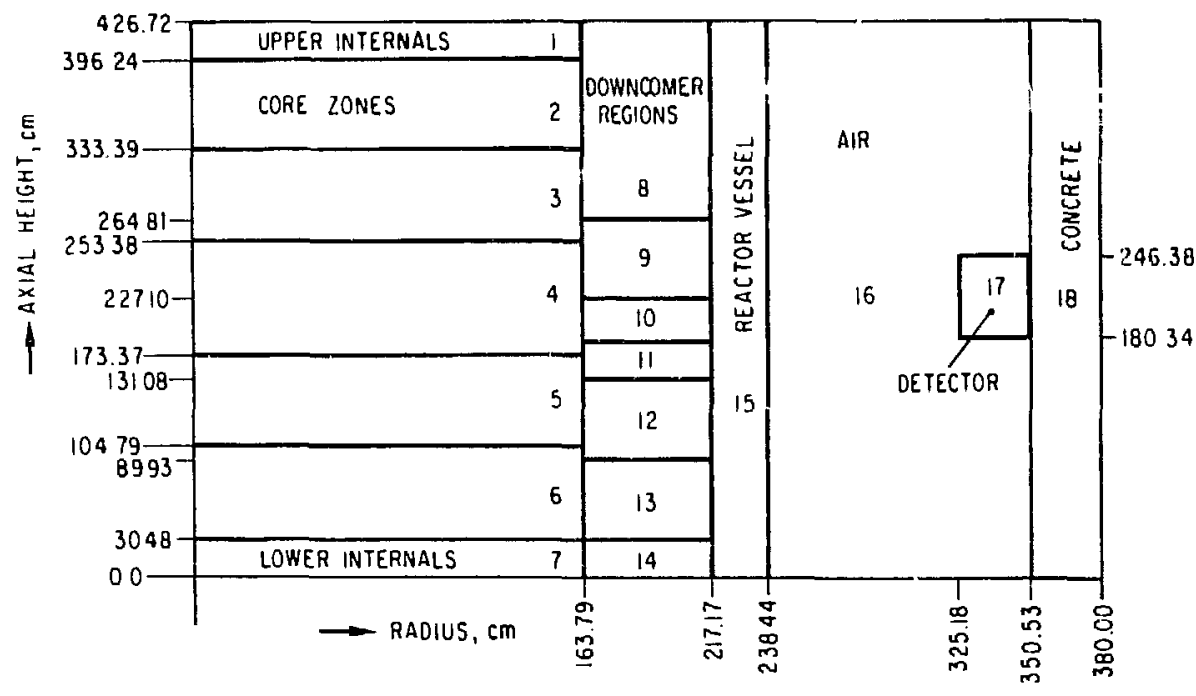

Fig. 3. Calculational RZ Model Geometry of TMI-2 Reactor Out to the Biological Shield

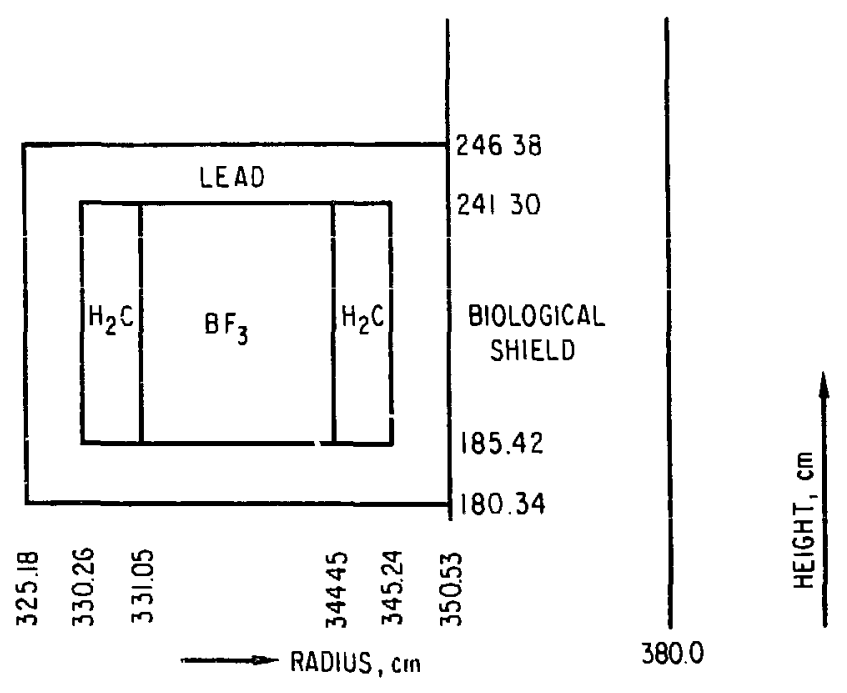

Fig. 4. Expanded Details of the Source Range Detector Area

The photoneutron source was approximated by applying a uniformly distributed volumetric neutron source throughout the core. The nominal volumetric source strength was chosen to be $6.25 \times 10^{3} \mathrm{n} / \mathrm{cm}^{3}-\mathrm{sec}$. With a core volume of 
$3.0826 \times 10^{7} \mathrm{~cm}^{3}$, the inferred total photoneutron source is $\sim 1.9 \times 10^{1 \mathrm{l}} \mathrm{n} / \mathrm{sec}$. core. This value corresponds to our estimate of tie photoneutron strength at about 30 minutes after the scram (see Fig. 1). It is thus an adequate initial value. The time variation of this can be easily factored in when applying tha results in part II to times other than this. Additionally, the nekilect of the spatial distribution of the photoneutron source should be a second-order effect due to the large mean-free paths of the high energy photons ( $>2.2 \mathrm{MeV})$ necessary to initiate the threshold $D(Y, n) H$ zeaction. The reduction of the source strength due to core voiding is approximated by reducing the nominal value by the factor $(1-v)$, with $v$ representing the void fraction.

It is also noted that the RZ calculational model necessarily yields an annular detector region rather than the actual discrete cylindrical shape. Thus, the results section will quote detector absorptions which are too large by a factor equal to the ratio of the volumes of the calculational model detector and the actual detector. This ratio is approximately 201.6.

\section{RESULTS}

The results of various static calculations are provided in this part. When significart mudel changes are introduced, they will be highlighted. If not mentioned, they will have failed to have an appreciable impact upon the $d$ r.tector response.

\section{A. Homogeneous Voiding Effects}

One of the more straightforward effects of the accident is the initial phase when the system was depressurizing during continued heat input via decay heat. There existed a sizable potential for the formation of relatively homogeneous voids within the primary loop. "P to the point of pump cavitation, or de-eiergization, the fluid would be relatively uniform in nature both in the core and downcomer. In order to quantify the interplay of the core voiding and the downcomer voiding effects, a sequence of homogeneous void calculations was created.

The reactor system was benchmarked at keff equal to unity with the rods out and $\sim 1700 \mathrm{ppm}$ of soluble boron present. (This level of soluble boron also accounts for the burnable poisons, $\sim 4.4 \% \Delta \mathrm{k} / \mathrm{k}$.) With the control rods inserted, again their worth was represented by boron, $k_{\text {eff }}=0.92$. From this assumed shut-down position (with a total boron level of 2600 ppm), calculations were made containing void fractions of $0.2,0.4,0.7,0.9$ and 1.0 , respectively. The void fractions were applied uniformly to the core, downcomer, upper and lower internal regions. The system eigenvalues are listed in Table II and are also illustrated in Fig. 5. Results for the cases near $100 \%$ void may be subject to error due to the extreme nature of the problem, however, the value of 0.313 for a dry core is consistent with typical values.

As the core voids, the photoneutron source decreases in strength concurrently with an increase of the leakage probability. More importantly, however, is the loss of "shielding" which occurs as the downcomer region voids. Even though tine neutron source strength is decreasing, the transmission probability (i.e. to the detector) is increasing at a greater rate. The 
TABLE II. Homogeneous Void Results

\begin{tabular}{lcc}
\hline Void Fraction & $k_{\text {eff }}$ & $\begin{array}{c}\text { Source Neutron Absorption } \\
\text { Probability in Detector }\end{array}$ \\
\hline 0 & 0.920 & $1.57 \times 10^{-7}$ \\
0.7 & 0.917 & $6.34 \times 10^{-7}$ \\
0.4 & 0.896 & $2.85 \times 10^{-6}$ \\
0.7 & 0.780 & $3.67 \times 10^{-5}$ \\
0.9 & 0.650 & $2.46 \times 10^{-4}$ \\
1.0 & 0.313 & $1.88 \times 10^{-3}$ \\
\hline
\end{tabular}

Detector Model - which is actually a ring around the vessel due to the $\mathrm{R}$. geometry, the ratio of actual detector volume to the model's volume is $4.961 \times 10^{-3}$.

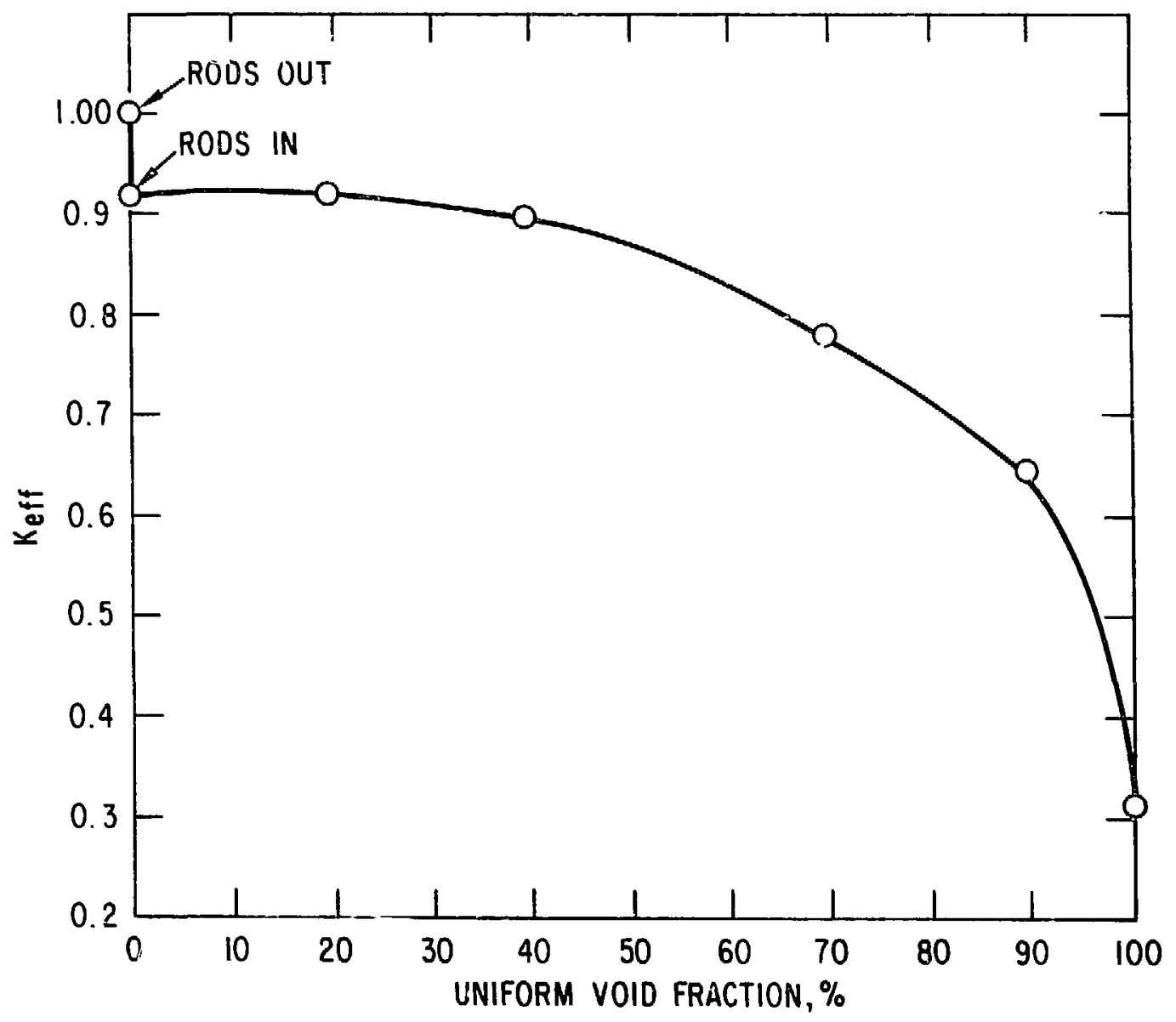

Fig. 5. Eigenvalue vs. Homogeneous Void Fraction 
result is a continually increasing count rate. Figure 6 illustrates the results for the detector absorptions (which, of course, are proportional to the count rate) vs. void fraction. The calculation of a value for a void fraction near 1.0 is not presented inasmuch as it would be highly speculative, That is, the exact value of the total source strength is some combination of very low order source strengths once the predominate photoneutron source is essentially eliminated, and is therefore difficult to quantify accurately.l As can be seen, homogeneous voiding can account for a maximum increase in the count rate of a factor of about 40. The transmission probability is defined as the ratio of the detector absorptions and the total neutron source. This quantity is shown in Fig. 7.

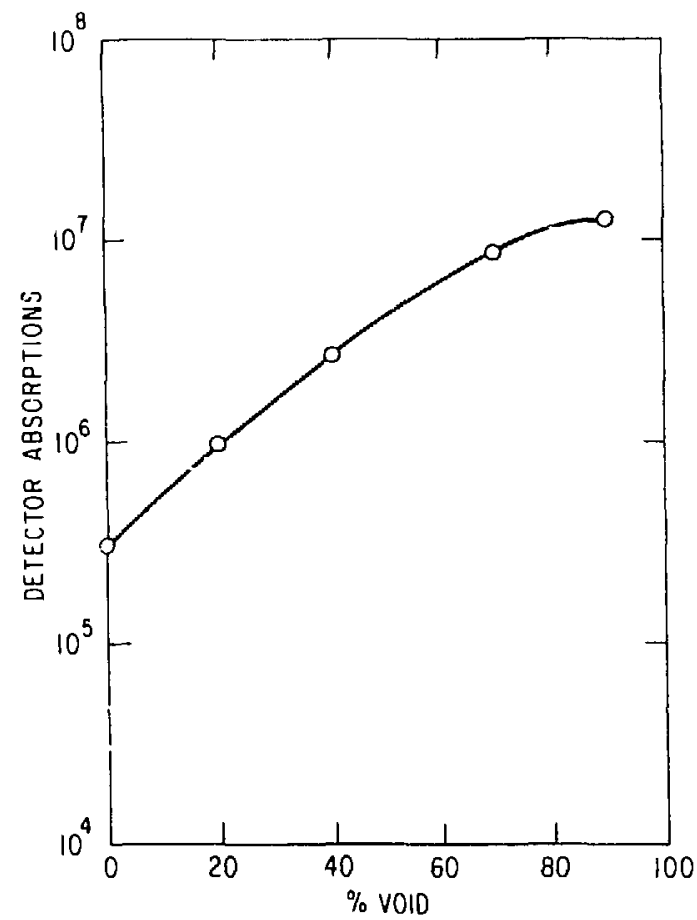

Fig. 6

Detector Absorptions vs. Homogeneous Void Fraction

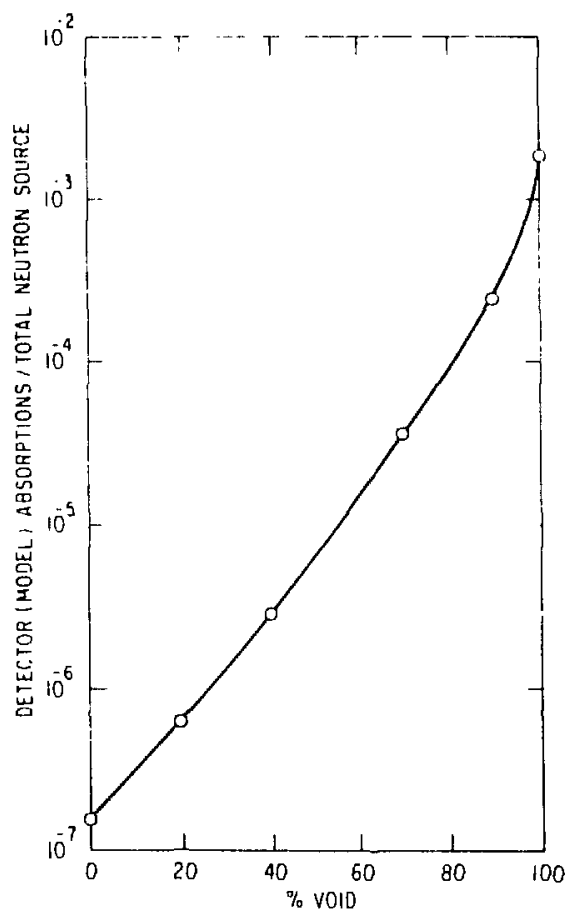

Fig. 7

Transmission Probability vs. Homogeneous Void Fraction

\section{B. Inhomogeneous Voiding Profiles}

The usefulness of the homogeneous voiding data is restricted to the first $\sim 1-1 / 2$ hours following the scram. Following this time, various initiating events, primarily the de-energization of the $A$ loop pumps, caused several diverse thermal hydraulic effects to occur: among them were temporary flow stagnation, vapor/fluid separation, spatially dependent voiding within the core, etc. This area of analysis is by nature much more speculative than in part A. However, reasonable assumptions can lead to data from winich general trends and global effects can be quantified. The following 
subsections describe three separate voiding model assumptions which were utilized in order to accomplish this.

1. Model $1-40 \%$ Maximum Void Up to

Based upon various thermal hydraulic considerations and the physical constants (specifically pressure and temperature) which were present during the $1-1 / 2$ to 3 hour period following the scram, it has been suggested that the core could have created a "stable" void profile in the axial direction. That is, there would be enough heat generated to create and maintain a certain maximum void fraction level. In particular, one hypothesis is that the void fraction would increase from 0.0 at the bottom of the active core to $\sim 0.4$ in about 2 to 3 feet. (Model 1 utilized a linear relation terminating arbitrarily at 2.44 feet.) Above this height, the void fraction would remain constant at this maximum value until the boil-off interface is encountered. Above this interface, the void fraction is assumed to be 1 . An additional and extremely important feature of this model is that the downcomer void fraction falls to zero after pump shutdown. The water level in the downcomer is ther dependent upon the gravity head in the cors. Due to the presence of the voids within the core, the downcomer water level is always lower than the coolant level in the voided core/upper internals region during this period (i.e. of low coolant inventory and absence of forced circulation).

The relative heights of the downcomer and core reginas were adjusted in the calculational model. (consistent with the above yravity head constraint) so that discrete points during a hypothesized boil-off proress could be calculated. The resulting count rates are once again, as during the homogeneous voiding process, a product of the interplay of the changing source strength in the core and both the amount and the location of the shielding provided by the downcomer water. This is best illustrated by examining the detector absorption vs. downcomer water level curve in Fig. 8.

As the downcomer water level approaches the top of the active core (12 feet), the count rate increases only slightly due to the increased transmission probaislity for the source which scatters and diffuses out of the top of the core. The next point of interest is when the downcomer level has lowered to a point of $\sim 7.7$ feet; at this point the gravity head of the nonvoided downcomer region exactly matches that of the voided cure. The detector absorptions increase very rapldly over this range as the core source strength remains essentially constant while the downcomer shielding is removed. When the downcomer level lowers further, the core water level now decreases or boils off as it continuously matches the gravity head of the downcomer. The detector absorption curve continues to rise, however, due to the fact that the core source strength is decreasing in a low worth area (i.e. the upper two feet of the active core) while the downcomer shielding is being removed at the point of its highest worth - near the 6 feet level. (The detector is located at the axial midpoint of the core -6 feet height。) Subsequent decreases in the water level begin to suituantially decrease the source strength with respect to the benefit of reduced shielding: the detector absorption rate thus begins to decrease. The maximum/minimum count rate ratio for the model 1 curve is $\sim 320$. 


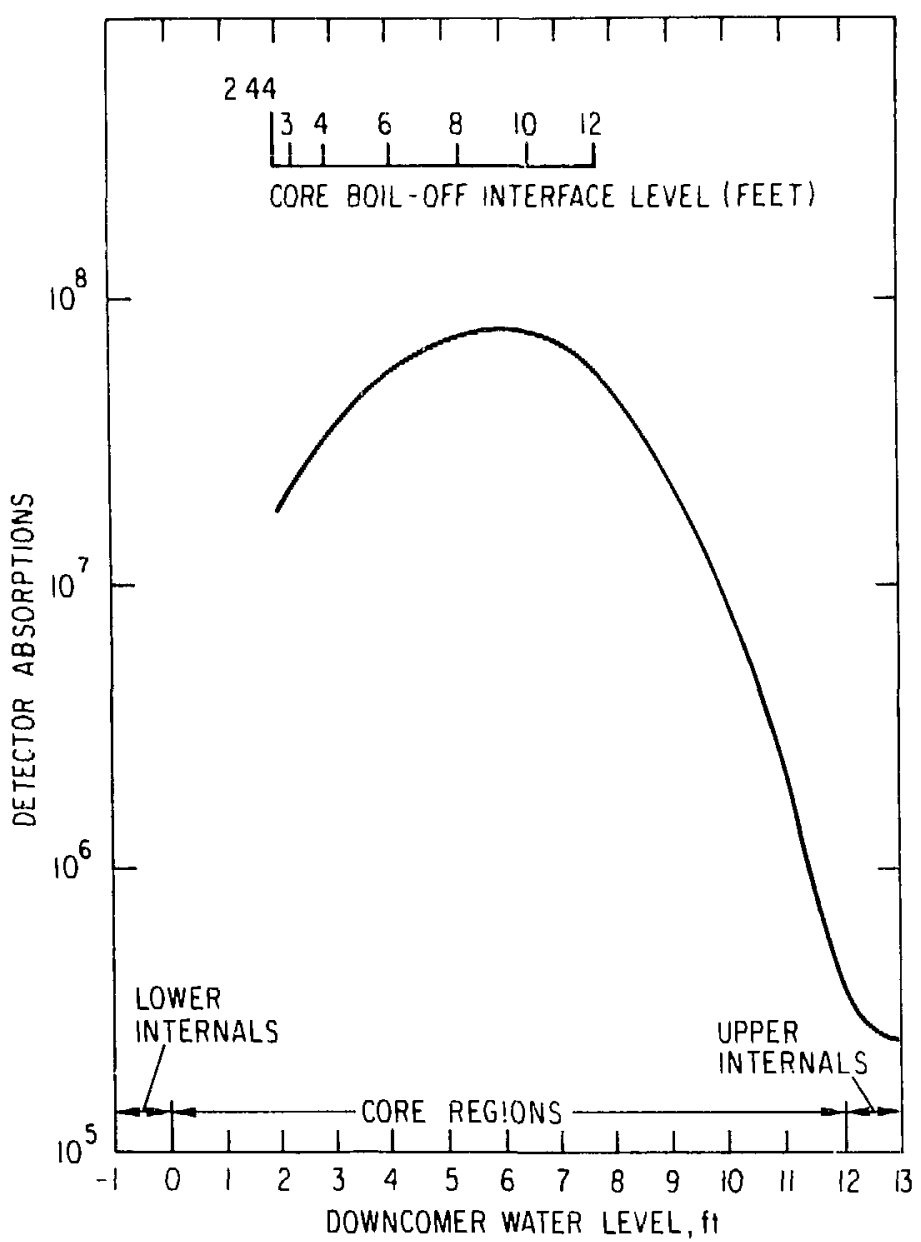

Fig. 8. Model 1 Detector Absorptions

vs. Water Level

In an effort to verify that, for example, subtle mesh instabilities or ray effects were not disturbing the $S_{4} P_{0}$ calculation, four sample calculations were repeated utilizing the VIM ${ }^{10}$ Monte Carlo code. VIM has been successfully utilized in benchmarking an LWR lattice, 11 and more importantly, accurately removes those calculatonal problems which are inherent in a transport solution. Especially with respect to the large air gap between the vessel and the detector, the Monte Carlo solution is clearly superior. In order to isolate strictly calculational problems, the transport result was normalized to the VIM boron cross section values in order to produce corresponding detector absorption rates. The results are listed in Table III.

It can te seen that no appreciable problems are evident in the transport calculation. Indeed, considering the severity of the problem from a quadrature point of view, the comparison is excellent. It appears from Table III that the transport model is of sufficient detall to expose the proper detector response trends to varlous core/downcomer conditions. 
TABLE III. Monte Carlo Benchmark of Transport Theory Solution

\begin{tabular}{|c|c|c|c|c|c|c|c|}
\hline Case & $\begin{array}{l}\text { Core Water } \\
\text { Leve1 (feet) }\end{array}$ & $\begin{array}{l}\text { Downcomer Water } \\
\text { Leve } 1 \text { (feet) }\end{array}$ & $\begin{array}{c}S_{n}\left(\times 10^{-5}\right) \\
\text { Detectol Abs./ } \\
\text { Total Source }\end{array}$ & $\begin{array}{l}\text { VIM }\left(x 1^{5}-5\right)^{\mathrm{a}} \\
\text { Detector Abs./ } \\
\text { Total Source }\end{array}$ & $\frac{V I M-S_{n}}{\text { Std. Dev. }}$ & $\begin{array}{l}\text { VIM } \\
\text { Eige nva lue }\end{array}$ & $\begin{array}{l}\text { Number of } \\
\text { Historles } \\
\text { (Thousands) }\end{array}$ \\
\hline 1 & 12.0 & 7.0 & 4.48 & $3.98 \pm 6.4 \%$ & 2.0 & $0.9136 \pm 11.0023$ & 80 \\
\hline 2 & 9.9 & 6.4 & 7.50 & $5.84 \pm 6.9 \%$ & 4.1 & $0.9115 \pm 0.0025$ & 50 \\
\hline 3 & 4.7 & 3.3 & 8.76 & $8.65 \pm 5.9 \%$ & 0.2 & $0.8966 \pm 0.0030$ & 55 \\
\hline 4 & 2.4 & 2.0 & 7.50 & $7.87 \simeq 4.6 \%$ & -1.0 & $0.8475 \pm 0.0018$ & 100 \\
\hline
\end{tabular}

${ }^{\text {a Track length estimator }}$

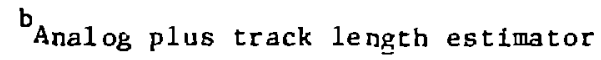


2. Mode1 2 - $30 \%$ Maximum Void Up to

Boil-off Interface, $95 \%$ Vo1d Above

The particular assumptions in Model 1 are based upon sound engineering judgment, but are none the less arbitrary. In order to quantify the sensitivity of the detector response to variations in the major assumptions, this second (and subsequently a third) model is introduced. The maximum al lowed vold level is reduced to $30 \%$ : again the vold fraction increases linearly from 0 at the bottom of the active core to 0.3 at a height of 3 feet. The height of the boil-off interface again depends upon the gravity head of the downcomer, however, the voided region above andior within the core is assumed to contain steam and water droplets, thus the $95 \%$ maximum void value above the boil-off interface. The calculational model's zone boundaries were adjusted from those in Fig. 3 so that the gravity head constraint was satisfied at various downcomer/wet core region combinations. The photoneutron surce is again proportional to $(1-v)$, with $v$ representing the roid fraction, and is spatially uniform in distribution.

A progression of calculations was made in a similar manner to section II.B.L in which the water level was sequentially lowered in the downcomer region - the core level followed at the appropriate level. The results are depicted in Fig. 9, which also crntains the Model 1 results for comparison. The two curves are very similar until the point of core uncovery is reached: apparently, to the first order, the increased source strength in Model 2 is roughly balanced by increased selfabsorption in the water. Due tu the lower void fraction, the downcomer gravity head cannot support as large a height of core as its corresponding point in model 1 , thus core uncovery occurs at a higher downcomer level. Given identical downcomer heights, Model 2 exposes sinaller axial portions of the wet core region, ${ }^{*}$ thus relatively lower detector absorptions despite higher volumetric photoneutron sources. For example, when the downcomer is at the 6 feet level, Model 2 predicts that two feet of wet core will be exposed to the detector while Model 1 predicts $\sim 3.3$ feet. Although Model 2 has a volumetric source strength which is $16.7 \%$ greater than Model 1 , the exposed area is $40 \%$ less; hence lower count rates. When the water levels are decreased further, the second difference in the models becomes apparent. At very low water levels, the wet core source is of low worth and the dryed

*For purposes of this discussion, the portion of the core which contains significant amounts of water (i.e. $v<0.4$ ) will be referred to as wet. 
out bulk of the core dominates the detector response. Model 1 , although at $100 \%$ void, contained a volumetric neutron source $1 / 100$ of the nominal photoneutron source in order to model the start-up source. Model 2, of course, has an assumed void fraction of 0.95 in the dryed out area: the source strength is therefore $5 \%$ of nominal, or a factor of five higher than Model 1 . As a result, the detector absorptions are higher for Model 2 at very low water levels.

The differences between the two nodels, however, are relatively small on a global basis. The detector response is not particularly sensitive to nominal sized changes in the specific assumptions. For Model 2, the max/min count rate ratio is $\sim 225$. This compares with a value of 320 with Mode 1 - a decrease of $30 \%$ with respect to Model 1 . The difference, however, is sinaller and less important than it seems at first. A significant portion of the shift $(11 \%$ of the $30 \%$ ) is due solely to the small difference in the respective minimurn values. This has little consequence upon any conclusions concerning the core uncovery process. More importantly, though, is the fact that global trends are the desired result. it would be inappropriate to claim, for example, that the core voiding and uncovery process can produce a change in the count rate of a factor of specifically 320 . It is quite clear, however, that this process can produce increases in excess of two orders of magnitude. This then, is the proper way in which to view the results.

An interesting way be which co examine the impact of the exposed wet core is shown in Fig. 10. In it, the detector absorptions for the two models are i) lustrated as a function of the differential between the downcomer water level and the we: core level. The importance of the location of the exposed wet core area is evident as the raximum detector absorptions does not occur at the point of maximum exposed wet core. This figure also demonstrates that the maximura amount of exposed wet core always occurs at the point of the initiation of core uncovery.

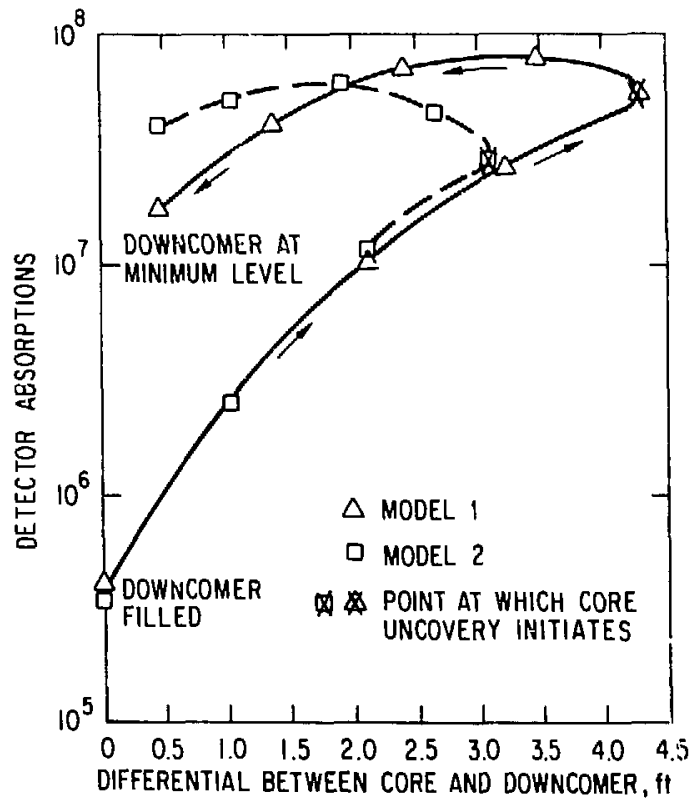

Fig. 10

Detector Absorptions vs. Wet Core/Downcomer Water Leve1 Differential 
3. Model 3 - 40\% Maximum Void up to Boil-off Interface, $95 \%$ Void Above, Axially Distributed Photoneutron Source Utilized

This third model combines what is considered to be the two most likely aspects of the previous models: i.e. a $40 \%$ maximum void level in the wet core regions with a $95 \%$ maximum void level in the dried out regions. The major difference is provided by the replacement of the spatially uniform distribution of the photoneutron source with a more realistic axially dependent source distribution. The photoneutron source will, to the first ipproximation, follow the fission product (thus power) distribution. The radial dependence is neglected as its effect will not alter the calculated trends, only the absolute magnitude of the count rate. However, given the resuits of the first two models which indicate a fairly sensitive interplay of source strengths and water levels, it is possible that an axially dependent source could alter the global trends. It is this concern that predicates this third model.

Model 3 has the void fraction increase linearly from 0 to 0.4 over the lower 4 feet of the active core height. The calculational model zone boundaries in the core and downcomer were again adjusted so that the gravity head constraint was satisfied. Physics calculations provided by TMi-2/ Metropolitan Edison personnel for the core as of March 19, 1979 yielded the predicted axial power distribution. This power distribution is then assumed to be equal to the fission product distribution, and thus the photon source. The data is Jisted below in Table IV.

TABLE IV. TMI-2 Axial Power Distribucion Centerline Fuel Assembly

\begin{tabular}{lcc}
\hline $\begin{array}{c}\text { Core Height } \\
\text { (feet) }\end{array}$ & $\begin{array}{l}\text { Interval Power } \\
\text { Level (kW/ft) }\end{array}$ & Normalized to 100 \\
\hline $0 \rightarrow 1.71$ & 5.38 & 8.47 \\
$1.71 \rightarrow 3.43$ & 9.14 & 14.39 \\
$3.43 \rightarrow 5.14$ & 10.24 & 16.13 \\
$5.14 \rightarrow 6.86$ & 10.74 & 16.91 \\
$6.86 \rightarrow 8.57$ & 11.00 & 17.32 \\
$8.57 \rightarrow 10.29$ & 10.28 & 16.19 \\
$10.29+12.00$ & 6.72 & 10.58 \\
\hline
\end{tabular}

An inspection of a sample of various other assembly locations in the core revealed that the centerline distribution was fairly representative. The normalized axial power distribution is illustrated in Fig. 11. This distributrion was applied by renormalizing it to the total neutron source which was assumed in Models 1 and 2. Thus, in a nonvoided configuration, the axially distributed source would produce the same total number of photoneutrons within the core as the uniform distribution does. During voiding and subsequent dry out, however, the sources will differ as the vold dependent term $1-v$ will be acting upon different local source strengths. The renormalized source itrengths for a nonvolded configuration are listed in Table V. 


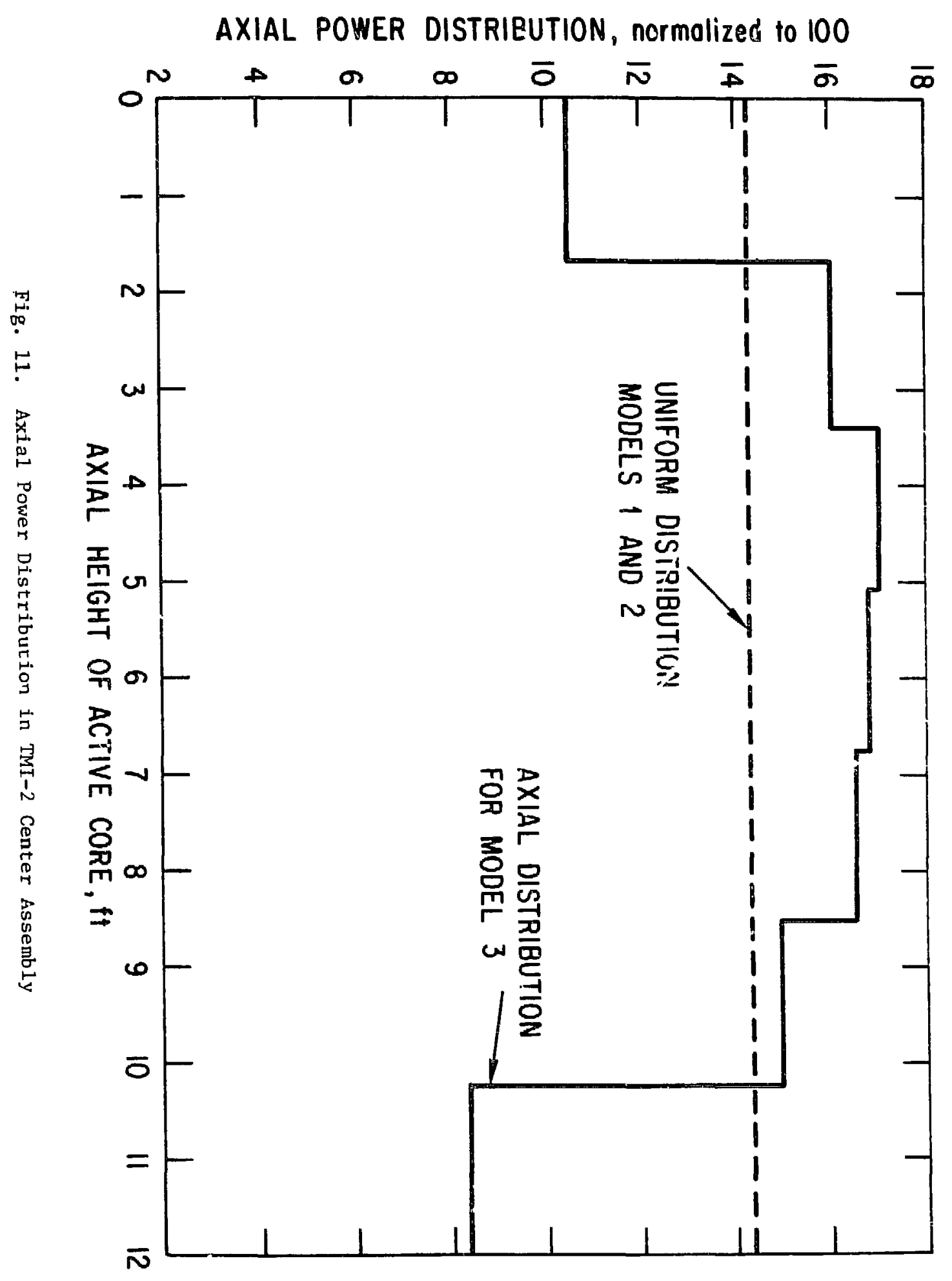


TABLE V. Axially Dependent Photoneutron Source Density for the Calculational Model

\begin{tabular}{|c|c|c|c|c|c|}
\hline \multirow{2}{*}{$\begin{array}{c}\text { Calculational } \\
\text { Core Region }\end{array}$} & \multirow[b]{2}{*}{ Height } & \multirow[b]{2}{*}{ (feet) } & \multicolumn{3}{|c|}{ Source Density $\left(\mathrm{n} / \mathrm{cm}^{3}-\mathrm{sec}\right)$} \\
\hline & & & Axially & Dependent, $\times 10^{3}$ & Uniform, $\times 10^{3}$ \\
\hline 1 & 0 & $\rightarrow \quad 1.71$ & & 4.60 & 0.25 \\
\hline 2 & 1.71 & +3.43 & & 7.00 & 6.25 \\
\hline 3 & 3.43 & +4.00 & & 7.44 & 6.25 \\
\hline 4 & 4.00 & $\rightarrow \quad 5.14$ & & 7.44 & 6.25 \\
\hline 5 & 5.14 & +6.86 & & 7.35 & 6.25 \\
\hline 6 & 6.86 & +8.57 & & 7.22 & 6.25 \\
\hline 7 & 8.57 & +10.29 & & 6.52 & 6.25 \\
\hline 8 & 10.29 & +12.00 & & 3.63 & 6.25 \\
\hline
\end{tabular}

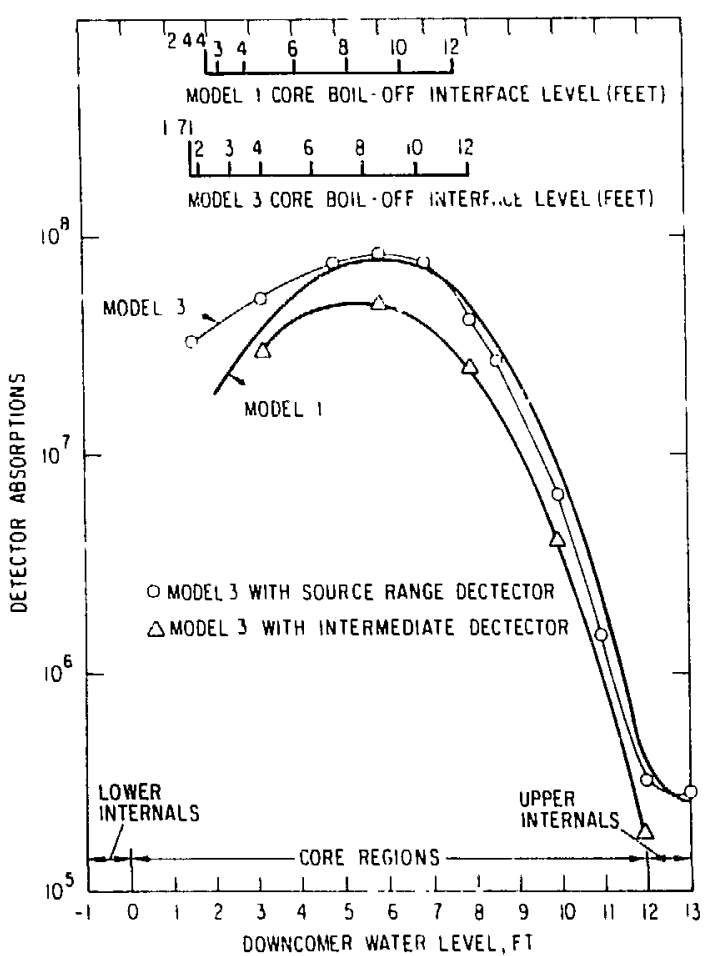

Fig. 12. Model 3 Detector Absorptions vs. Water Level
Figure 12 illustrates the results of Model 3. The minor differences from Model 1 are relatively easy to explain. The lower values during the initial lowerering of the downcome $r$ level art due to the importance of the source in the upper region of the cors. Due to the axial distribution, it is lower with respect to the uniform distribution. Once the middle portion of the wet core becomes exposed, the advantage shifts to Model 3 as the higher source density regions in the center area lead directly to higher count rates. The higher detector absorptions at very low water levels is a result of the assumption of a maximum void fraction of 0.95 in the dried out portion of the core. This higher photoneutron source with respect to Model 1 makes up for the fact that the Model 3 source in the lower core region is smaller than in the uniform distribution. The count rate max/min for this model is 300 : the conclusions mentioned in Section II.B.2 concerning two orders of magnitude increases in the count rate due to core uncovery are still valid.

\section{Intermediate Range Detector Response}

The intermediate range detector has a considerably different geometry from the source range detector. It has a 4-in. lead shield as opposed to $2-i n$. and its active height is $14 \mathrm{in}$. rather than $26 \mathrm{in}$. The diameter of 
the $\mathrm{BF}_{3}$ zone is the same as the source range detector. As a result, the above changes effectively move the centerline of the detector 2.1 in. closer to the reactor vessel. In consideration of the possibility that the differing geometry could yield an altored response, five cases were recalculated utilizing Model 3 assumptions with the source range detector replaced by the intermediate range geometry.

The five resulting data pints are shown on Fig. 12. As is expected from the presence of increased shielding from the lead and the decrease in active detector volume, the count rates decrease with respect to the original Nodel 3 results. Incidently, the decrease is by almost a uniform amount of $\sim 40 \%$. No surprising trends or variations are evident from this permutation of the detector geometry. In addition to indicating that the intermediate range detector should respond in a simflar manner as the source range detector does, the results indicate that the basic global trends are not acutely dependent upon the specifics of the datector model.

D. mpact of Downcomer Bypass Region and Released Source in Downcomer

Two relatively straightfurward permutations are addressed in this section. First, the downcomer region is split into 2 radial zones: the inner zone is allowed to follow the core void fraction and height. The second effect is the impact upon detector response which a distributed soucce within the downcomer region has.

\section{Effect of a Split Downcomer Region}

It has been postulated that the bypass region of the reactor would receive sufficient heat that it would follow the core coniguration rather than the downcomer. Up to this point, the bypass region has been lumped together with the other regions between the reactor and its vessel. "Thus a massive calculational "downcomer" region. In this model, the bypass region (radius of $163.8+179.1 \mathrm{~cm}$ ) is allowed to exhibit the void fraction and wet level of the core. The outer downcomer (radius of $179.1+217.2 \mathrm{~cm}$ ) acts as it did previously.

Results for this calculation are shown in Fig. 13. Basically, the bypass region acts to shield the exposed area of wet core as it follows its level exactly and count rates are decreased over the entire curve with respect to Model 1 . The exception is when the downcomer is completely filled and there is no exposed wet core to shield. In this case, the voided bypass region increases transmission slightly and therefore increases count rates. The approximate max/min is reduced to $\sim 75$.

\section{Effect of A Hypothetical Source Within the Downcomer}

There exists the possibility that following core uncovery, fission products became distributed within the downcomer water as a result of global fuel pin failure via clad oxidation and embrittlement. Fission products within the downcomer water would cause photoneutron sources which are signiFicantly more effective with respect to detector absorption than those within the core. The magnitude of the source, however, probably would not be that large with respect to the total core source. For example, the combination 


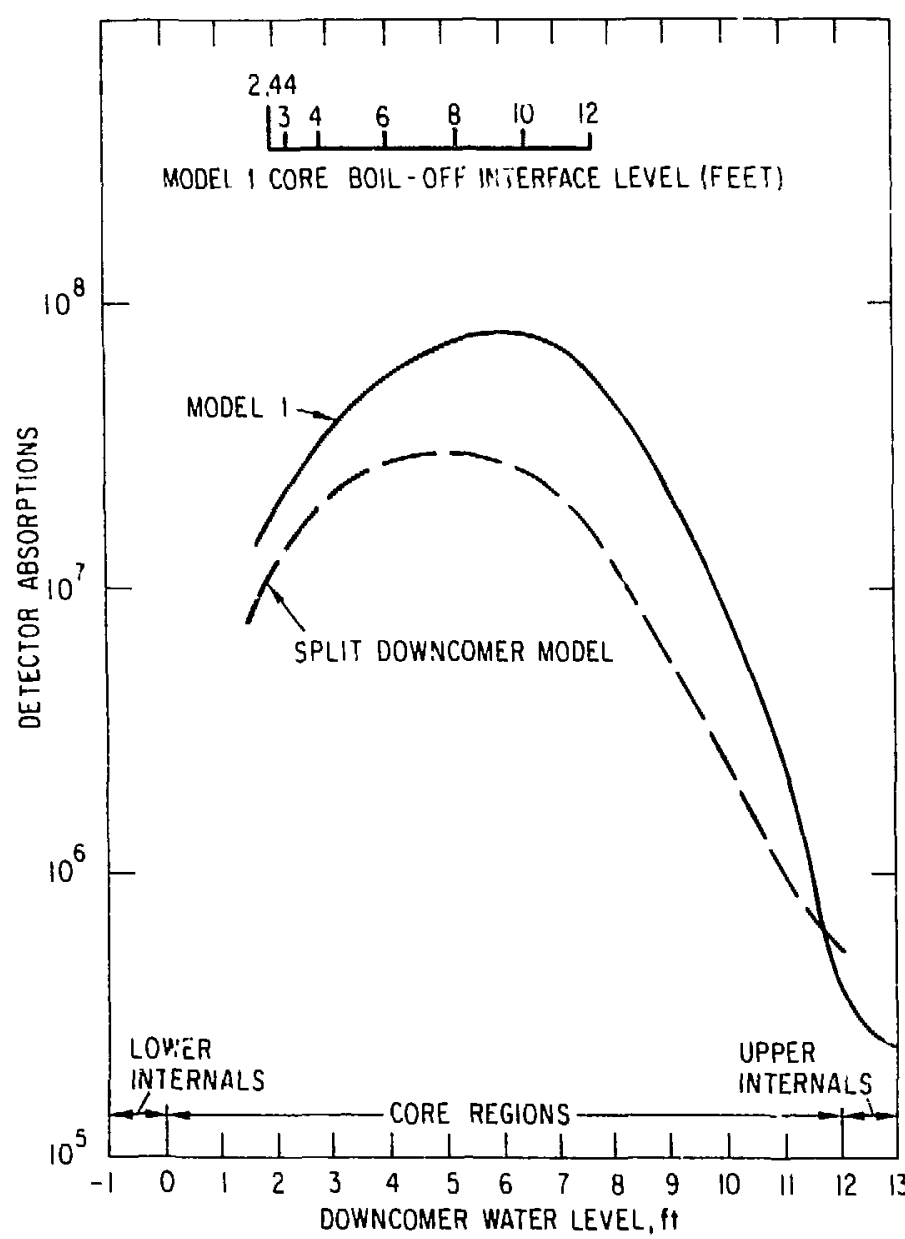

Fig. 13

Split Downcomer RegionDetector Absorptlons vs. Water Leve1

of assumed fission product release fractions and subsequent dilution within the coolant inventory could easily reduce the potential source to $\ll 10 \%$ or the theoretical core maximum. With this in mind, the potential effectiveness of a neutron source within the downcomer was quantified by placing a uniform distribution of the nominal photoneutron source at arbitrary values of $1 \%$ and $2 \%$ of the full strength value.

The effect of this source is seen in Fig. 14 as the above mode 1 of Section II.D.1 was utilized. When the downcomer is relatively full and substantially shielding the core, the newly placed source has a significant impact upon the count rate. With the downcomer fully filled, the count rate is increased by factors of 4 and 7 , respectively, with respect to the results without a downcomer source. As the wet core is exposed, the source from the core outweighs the source from the downcomer. At the point of core uncovery (downcomer at 8 feet), the count rates among the three cases are within $\sim 20 \%$ of each other. After further uncovery, the 3 curves merge. The effect of the downcomer source is primarily to alter the minimum count rate: thus the nax/min ratio for the $1 \%$ and $2 \%$ cases are merely $\sim 14$ and $\rightarrow$, respectively. The maximum value is left unchanged. 


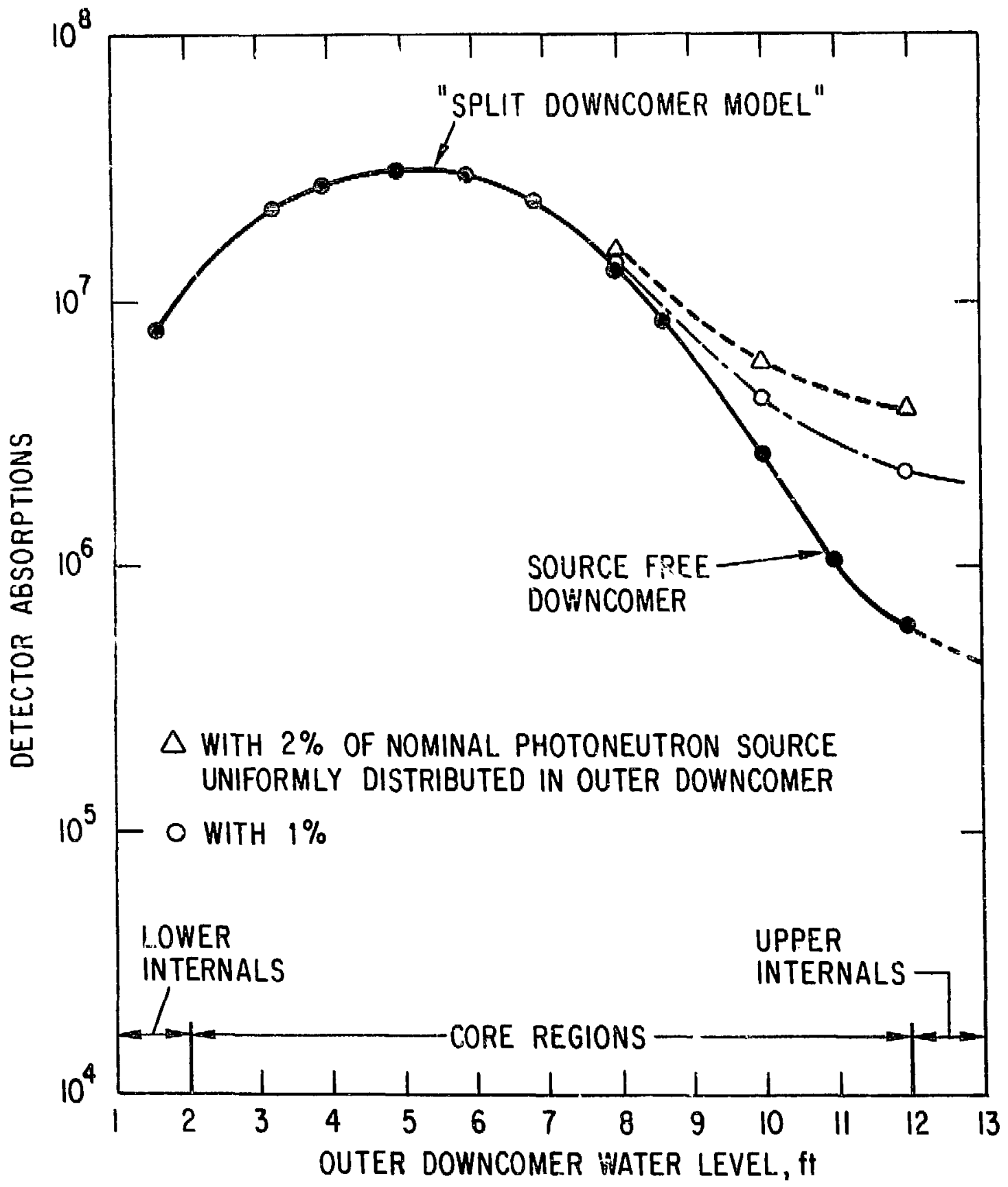

Fig. 14. Effect of a Hypothetical Source Within Downcomer Detector Absorptions vs. Water Level 
I II . SUMMARY

The results in part II quantify estimates of the detector count rate changes which can be expected from various combinations of water conditions within the core and downcomer regiol.s. They will now be linked to the actual response of the detector in order to provide possible interpretations for the anomalous count rate behavior. Figure 15 illustrates the TMI-2 source range detector's response up to four hours following the scram.

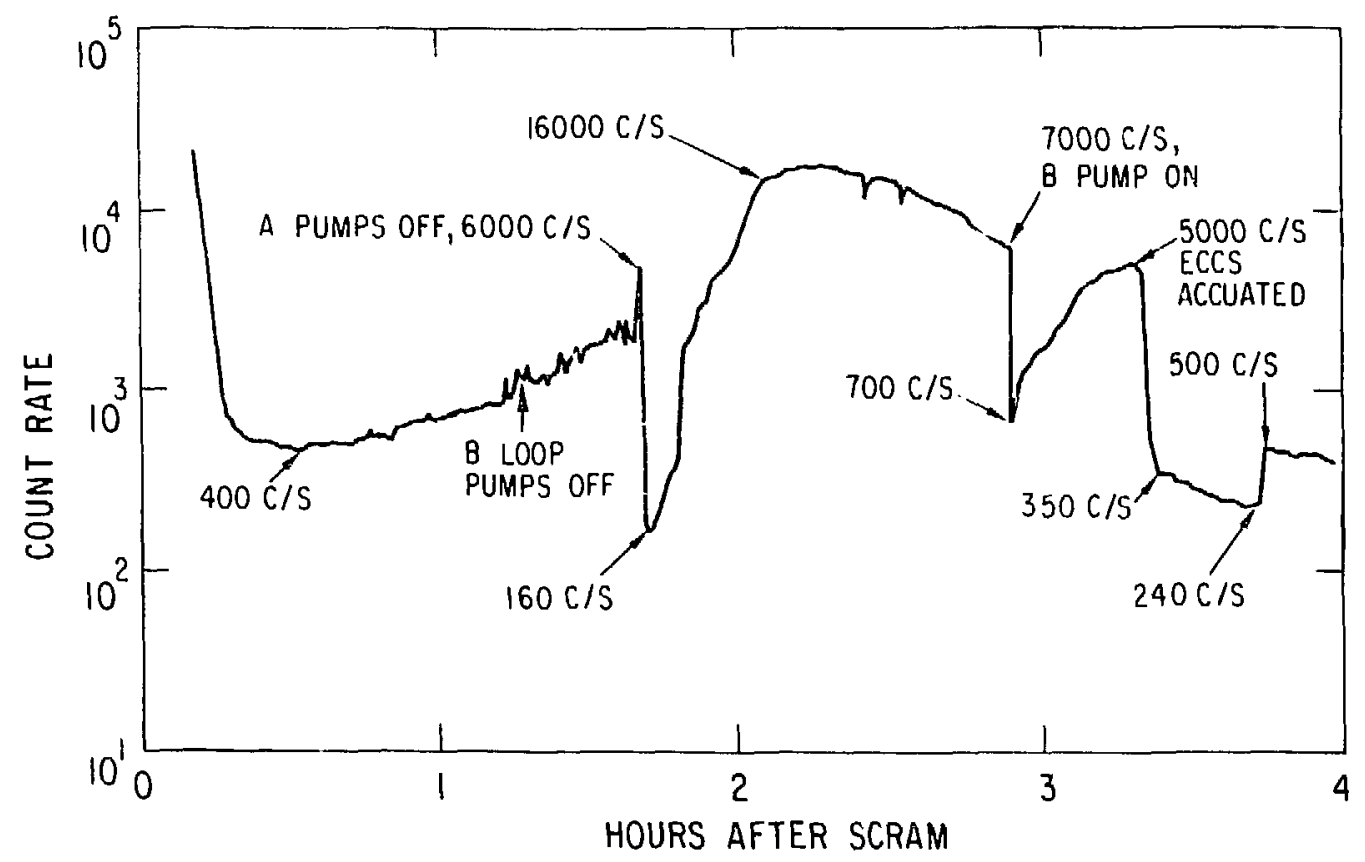

Fig. 15. Ex-Vessel Source Range Detector Response: $0 \rightarrow 4$ hours

A. Period of Approximate Homogeneous Voiding ( 0 to 1 hour 40 minutes)

The anomalous behavior is initiated at 30 minutes when the detector count rate ceases a normal monotonic descent and starts to slowly increase. The subsequent period of relatively gradual increases ends abruptly at $\sim 1$ hour 40 minutes. During this time period, the primary system is depressurizing and losing coolant through the failed block valve. Excessive pump vibrations lead to the de-energization of the $B$ loop pumps at about -1 hour and 14 minutes, the A loof pumps at $\sim 1$ hour 40 minutes (each loop has 2 pumps). The combination of pressure, heat source, lack of heat sink and low coolant inventory could have led to the initiation of voiding within the core. As time progressed, the voiding could have spread throughout th.? entire primary loop. The driving force of the pumps would have tended to maintain fairly uniform void profiles within the system, specifically within the core and downcomer. Therefore until the final pumps were de-energized, an approximate uniform void condition could have begun with gradually increasing void content with respect to time. 
The maximum change in count rate uver this period of time is approximately a ractor of 15 increase $(6000 / 400=15$, see Fig. 15). The results for homogeneous voiding in Section II.A indicate that a maximum increase in the sount rate of a factor of $\sim 40$ could be experienced if the void fraction increased from $0+0.95$. However, a void fraction of 0.95 would have becin difficult to actieve. Pump cavitation is predicted to occur near $\sim 60 \%$ void content. Correspondly, the exct"sive punp vibration which reulted in the decision to de-energize the Las remaining coolant pumps was indicative of rump cavitation. Therefore, a more realistic prediclion of the maximum inirease in count ate would be the change depicted in Fig. 7 between a void ontent of 0 and $\sim 60 \%$ : an ini:rease by a lactce of 20 is predicted. Photoneutron decay over this time period would reduce this value to $~ l l$ (see Fig. 1). This value demonstrates the ctedibility oi the hourgeneous voiding sienariu over this time period..s it compares favorably with the actual increase of a factor of ?5.

B. Period of Inhomogeneous Voiding and Coolant Levil Irregularities ( $>1$ hour 40 minutes)

Following the de-energization of the last remaining pumps at 1 hour 40 minutes, various events during the next few hours lead to inhowogeneous voiding and rapidly changing water leveis. The more obvious initiating events are the restarting of primary loop pumps or actuation of the ECCS both provide rapid influxes of water to the downcomel and core. More subtle changes also impact the detector response: block valve reclosure, passible core rearrangement, spatially inhrmogeneous voiding, etr. All of these events, an! potentially sume as yet unspecified ones, interacted to yield the actual time dependency of the delector response. The inhomogeneous voidirb' zasults rom part II.B and D are now utilized to provide possible interpretations of the detector response after 1 hour 40 minutes.

At the time of the last A loop pump de-snergization, the count rate had reached a local maximum of $\approx 6060 \mathrm{cps}$. There follows on Fig. 15, an almost immediate drop to the minimum value of $160 \mathrm{cps}$ - a factor of 37.5 decrease. This can be explained by considering that the homogeneously voided coolant would undergo a phase separation when the pump's driving force is eliminated: solid water would fall ro fill the downcome: - thus eflectively shielding the detector. [The decay of the photoneutron source is negligible during these few minutes, thus values need not be corrected for time effects.] The effect of instantaneous collapse of a homogeneously voided core/downcomer can be extracted directly from Fig. 6.

However, an instantaneous collapse is impossible to achieve due to the pressure drop within the core: the downcomer would most likely refill prior to $100 \%$ refill within the core. Thus, the nonvoided downcomer would be shielding the detector from a core which had less of a photoneutron source than the instantaneous collapse model predicts. The result, of course, is lower count rates for a short time as the core completes its refill process: this results in an increase in the effective count rate reduction factor from that value which would be predicted via the instantaneous model. Viewed in this fashion, it can be sees that reduction value factors extracted from Fig. 6 (say, e.g., $20+35$ ) then compare favorably with the detector decrease of $\sim 37.5$. 
The next portion of the count rate response to be examined is the period from the minimum achieved count rate ( $160 \mathrm{cps}$ at $\sim 1$ hour 42 minutes) to the point at which the $B$ loop $B$ pump was restarted at 2 hours 53 minutes. This period of time first has a marked increase in count rate over a short time period (increases by a factor of 100 over $\sim 20$ minutes) and then, after reaching a maximum near the 2 hour 23 minutes mark, decreases less rapidly (by only a factor of $\sim 2.3$ ) until the point at which a $B$ loop pump was restarted. This portion of the curve is compared directly with the results depicted in Figs. 8, 9, 12 and 13; 1.e. Models 1,2 and 3 .

The accident, at this point, was still a small break LOCA as the block valve was not reclosed until near the 3 hour mark. With the absence of forced circulation, the decay heat was removed via natural circulation. Unfortunately, there did not exist a sufficient coolant inventory to accommodate this process due to the depressurization and steam venting. As a result, core boil-off most probably ensued. The effect of this particular process was quantifled in the above mentioned figures: the results have two sallent features. First, that the downcomer level has the most immediate and significant impact upon the detector response. IAll of the figures reflect this, however, Fig. 12 will be utilized as a source to provide quantitative examples.] The downcomer level drops as the core undergoes the voiding process. The count rate increases, e.g., by a factor of 100 as the downcomer drops just 3-1/2 feet below the top of the active core. The total max/min factor 1s 300. This illustrates that the position of the downcomer can easily account for the actual count rate response increase of a factor of 160. Specifics of exactly where the downcomer water level is with respect to time and count rate is not feaslble within the context of this approximate work. However, all results clearly illustrate that a factor of 100 increase in the count rate is achievable during the initial phase of core boil off. Even the inclusion of a split downcomer region (Fig. 13) does not preclude a two order of magnitude increase in the count rate.

The second important feature of the inhomogeneous results is the possibility that the slowly decreasing count rate could be the result of continued core boil off once the maximum count rate value has been reached. The shape of the count rate response during this period of time ( 1:50+2:50) qualitatively matches that of the results presented in Section II.B. of course, a gradual refill in the downcomer or the core region could produce the decreasing count rate, too. It would be too speculative to conjecture which scenario is more likely. Nevertheless, the boil off process and the downcomer water level can explain the detector behavior qualitatively over the period of 1 hour 40 minutes to 2 hours 53 minutes, at which time a B loop pump restarted and initiated further developments.

Subsequent events can be intergretted in a similar fashion to the above. The startup of a B loop pump deliveicd flow to the downcomer for approximately 8 seconds - in an analogous fashion to the phase separation and downcome $r$ refill described earlier, an immediate and substantial decrease in the count rate is expected and seen in Fig. 15. Simflarly, the ECCS actuation at $\sim 3$ hours 20 minutes leads to a rapid decrease in count rate as the downcomer is again refilled. Following each of these events, count rate variations can be expected due to the possibility of water level readjustment, core rearrangement, fission product release, small scale boll off, etc. A combination of 
quantified effects from Section II can be uciiized to explain the trends and, to some extent, the magnitudes of the count rate changes in Fig. 15 .

As discussed above, most of the anomalous neutrun detector readings could be correlated witn the known sequence of events, and some inferences could be made with respect to the cort lydraulic conditions. However, because the core neutronic and hydraulic conditions during the TMl-2 incident are not precisely known, uncertaiusies are introduced and explicil quantitative analyses of the reteccor response do not appear teasible. Nevertheless, the detector response is imporcant information which, along with ocher instrumentation daca and chermal-hydraulic analyses, could be correlated in orcier to provide a self-consistent scenario of core conditions luring the [M-11-2 : Itin:.

\section{W. AL'KNOWLEDCHENTS}

The authors gratefully acknowledge the assistance provided by $\mathrm{C} . \mathrm{H}$. Adams, L. K. Fujita, E. M. Gelbard and L. J. Milton, who provided considerable calculational and advisory assistance during the relatively short veriod of time over which this ury had co be completer. Aiso, R. Henry and P. Abramson are recognized for Iurnishing the spatially dependent void profile model and other thermal hydraulic intormation. 


\section{REFERENCES}

1. Chisholm, G. H. and Malloy, D. J., "Summary of the Scenarios presented by the NRC and NSAC Concerning Damage to the TMI-2 Core," IntraLaboratory Memorandum, Argonne National Laboratory, February 27, 1980.

2. "Analysis of Three Mile Island - Unit 2 Accident," Nuclear Safety Analysis Center, Electric Power Research Institute, NSAC̄-1, July 1979.

3. Kemeny, J.G., et al., "Report of the President's Commission on the Accident at Three Mile Island," Uctober 30, 1979.

4. Ferguson, D. R. and Derstine, K. L., "Optimized Iteration Strategies and Data Management Considerations for Fast Reactor Finite-Difference Diffusion Theory Codes," in the Proceedings of the Meeting on Improved Methods for Analysis of Nuclear Systems, Tucson, Arizona, March 1977.

5. Cobb, W. R., Eich, W. J. and Tivel, D. E., "Advanced Recycle Methodology Program System Documentation, EPRI-CELl Code Description," Part II, Chapter 5, Electric Power Research Institute, October 29, 1975.

6. Bell, M. J. "ORIGEN - The ORNL Isotope Generation and Depletion Code," Oak Ridge National Laboratory, ORNL-4628, May 1973.

7. Kichings, H. J. "TMI-2 Event Ex-Core Neutron Detector Readings: Cause and Significance," Memorandum to R. Mattson, Nuclear Regulatory Commission, August 24, 1979.

8. Malloy, D. J., "kevised Neutron Flux Level Estimates for the Three Mile Island - Unit 2 Core," Intra-Laboratory Memorandum to Y. I. Chang, Argonne National Laboratory, July 30, 1979.

9. Malloy, D. J., "Photon Absorption Rate in the Coolant of Three Mile Island - Unit 2 Core," Intra-Laboratory Memorandum to Y. I. Chang, Argonne National Laboratory, July 6, 1979.

10. Prael, R. E. and Milton, L. J., "A User's Manual for the Monte Carlo Code VIM," Argonne National Laboratory, FRA-TM-84, February 20, 1976.

11. Malloy, D. J. and Chang, Y. I., "Effects of Burnup and Fueling Options Upon Fuel Utilization Characteristics of the Light Water Backfit High Gain Converter," Argonne National Laboratory, RSS-IM-16, Decenber 3, 1979. 
APPENDIX A: CALCULATIONAL MODEL MATERIAL DESCRIPTION

The calculational model which was utilized in this work is described in a general fashion in Section I.C. This appendix presents the more detailed specifics of the materials which comprise the model.

As mentioned previously, the model which was utilized by the Nuclear Safety Analysis Center (NSAC, operated by the Electric Power Research Institute) was adopted in order to provide some degree of consistency with other calculations. Table A-1 reflects this information as it lists the materials and volume fractions appropriate for each region. The region numbers correspond to those in Fig. 3, which is included here as $\mathrm{Fig}$. A-1. The detector reglon (number 17) is shown in expanded detail in Fig. A-2: the three detector materials (lead shielding, polyethylene and $\mathrm{BF}_{3}$ ) each have a volume fraction of 1.0 within their respective subregions.

TABLE A-1. Kegion Desiription: TMi-2 RZ Calculation Model

\begin{tabular}{|c|c|c|c|}
\hline Region Number & Region Description & $\begin{array}{l}\text { Basic Materials } \\
\text { Present }\end{array}$ & $\begin{array}{l}\text { Approxinate } \\
\text { Volume } \\
\text { Fraction }\end{array}$ \\
\hline 1 & $\begin{array}{l}\text { Upper Core Internals } \\
\text { (includes outlet plenum, ete.) }\end{array}$ & $\begin{array}{l}\text { Coolant } \\
\text { Stainless Stee } \downarrow\end{array}$ & $\begin{array}{l}0.886 \\
0.114\end{array}$ \\
\hline $2+6$ & rore Zones & $\begin{array}{l}\text { Coulant } \\
\text { Fuel } \\
\text { Zr } \\
\text { Control Rods }\end{array}$ & $\begin{array}{l}0.5943 \\
0.2904 \\
0.0968 \\
0.0185\end{array}$ \\
\hline 7 & $\begin{array}{l}\text { Lower internals ( } 1 \text { noludes } \\
\text { inlet pltaum, spacer } \\
\text { plite, ete.) }\end{array}$ & $\begin{array}{c}\text { Coolant } \\
\text { Stainless Steel }\end{array}$ & $\begin{array}{l}0.803 \\
0.1970\end{array}$ \\
\hline $8+14$ & $\begin{array}{l}\text { Homogenized Downcomer } \\
\text { (ineludes core liner, water } \\
\text { gaps, thermal shield, core } \\
\text { barrel and downcomer) }\end{array}$ & $\begin{array}{c}\text { Coolant } \\
\text { Stainless jteel }\end{array}$ & $\begin{array}{l}0.739 \\
0.261\end{array}$ \\
\hline 15 & Reactor Vessel & Carbon Steel & 1.0 \\
\hline 16 & Air Gap & Standard A1r & 1.0 \\
\hline 17 & Detector & Lead, Polyethlene, $\mathrm{BF}_{3}$ & $\begin{array}{l}\text { As specified } \\
\text { in Fig. A-2 }\end{array}$ \\
\hline 18 & Biological Shield & Concrete & 1.0 \\
\hline
\end{tabular}

The number density information for the basic materials is presented in Tables A-2 throngh A-4. Generally, the number densities were taken directly from the NSAC model description. If a material was not included in the NSAC model, e.g. polyethylene, the number density was created from first principles. Certain trace nuclides in some materials were omitted in the interest of expediency: e.g. F, Si and Mn. Their neglect has virtually no impact upon the neutronics of the material properties. Other trace nuclides, whose cross sections were unavallable on a timely basis, were approximated via a 


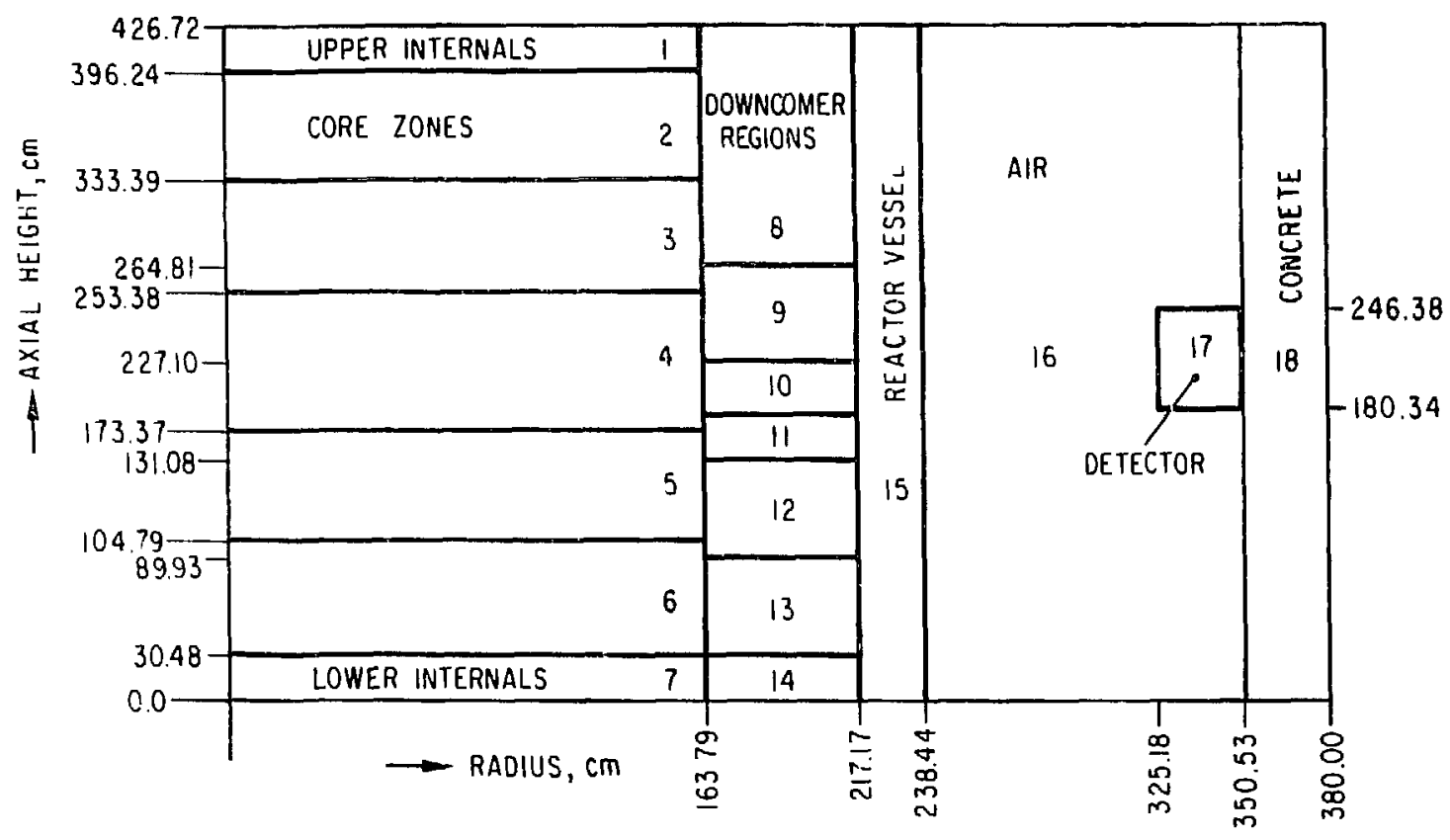

Eig. A-1. Calculational RZ Model Geometry of TMI-2 Reactor out to the Biological Shield

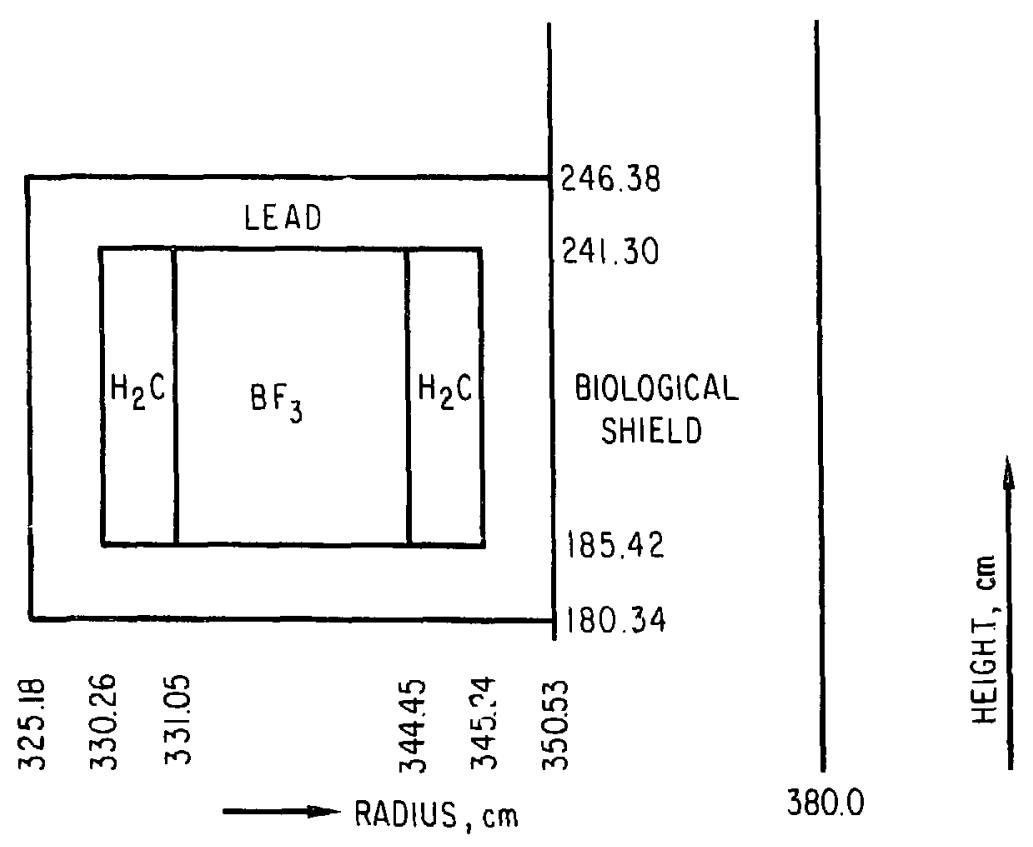

Fig. A-2. Expanded Details of the Source Range Detector Area 
TABLE A-2. Trace Nuclide Replacement Scheme

\begin{tabular}{ccc}
\hline & $\begin{array}{c}\text { Equivalent Number of } \\
\text { Replacement Acoms } \\
\text { Per Original Atom }\end{array}$ \\
\hline $\mathrm{Na}$ & $\mathrm{Cr}$ & $1 / 7.75$ \\
$\mathrm{Mg}$ & $\mathrm{Fc}$ & $1 / 42.5$ \\
$\mathrm{~K}$ & $\mathrm{Cr}$ & $1 / 1.5$ \\
$\mathrm{Mn}$ & $\mathrm{Ni}$ & 3 \\
$\mathrm{Al}$ & $\mathrm{Fe}$ & $1 / 11$ \\
\hline
\end{tabular}

TABLE A-3. Lalculational Model Composition of Reactor Vessel Steel Number Density

\begin{tabular}{|c|c|c|c|c|c|}
\hline \multirow[b]{2}{*}{ Nuclide } & \multicolumn{4}{|c|}{ Number Density } & \multirow{2}{*}{$\begin{array}{l}\text { Percent Change } \\
\text { from Nominal }\end{array}$} \\
\hline & Nominal & Carbon & Equivalent & Carbon & \\
\hline $\mathrm{Fe}$ & 8.1979 & $-2^{a}$ & 8.19854 & -2 & 0.008 \\
\hline Cr & 1.2746 & -4 & 1.27460 & -4 & - \\
\hline $\mathrm{Ni}$ & 4.8377 & -4 & 7.84775 & -4 & 62.2 \\
\hline$M r$ & $1.12 \cup 1$ & -3 & 1.12010 & -3 & - \\
\hline $\mathrm{C}$ & 8.6707 & -4 & 8.6707 & -4 & - \\
\hline $\mathrm{Si}$ & 4.2641 & -4 & - & & \\
\hline Mo & 2.7137 & -4 & - & & \\
\hline $\mathrm{Ca}$ & 1.1175 & -4 & - & & \\
\hline AL & 7.0177 & -5 & - & & \\
\hline
\end{tabular}

${ }^{\mathrm{a} e a d}$ as $8.1979 \times 10^{-2}$.

simple nuclide substitution scheme. When a nuclide was to be replaced, an available nuclide with similar neutronic properties was chosen as its substitute. The relative proportions of thermal capture, scattering and the resonance integral value from BNL-325 were compared among the orfginal nuclide and 3 arbitrary candidates for substitution: $\mathrm{Cr}, \mathrm{Fe}$ and $\mathrm{Ni}$. That isotope which most closely matched the proportions for the original nuclide was selected. The equivalent number density was then set by ratioing the thermal $(n, \gamma)$ cross section value of the two nuclides. Table A-2 illustrates the resulting equivalences which nominally preserve thermal capture reaction rates.

Table A-3 illustrates the implementation of the trace nuclide replacement scheme upon the reactor vessel carbon steel. As can be seen, changes are minor with respect to the total composition. Given that the replaced nuclides constitute a very small portion of the total material, it is deemed adequate to represent them in such an approximate fashion.

Soluable boron and both the burnable poison $\left(\mathrm{B}_{4} \mathrm{C}\right)$ and control material were modeled as an equivalent amount (reactivity-wise) of $\mathrm{B}-10$. This 
TABLE A-4. Homogenized Number Densicles; TML-2 RZ calıulational Mour

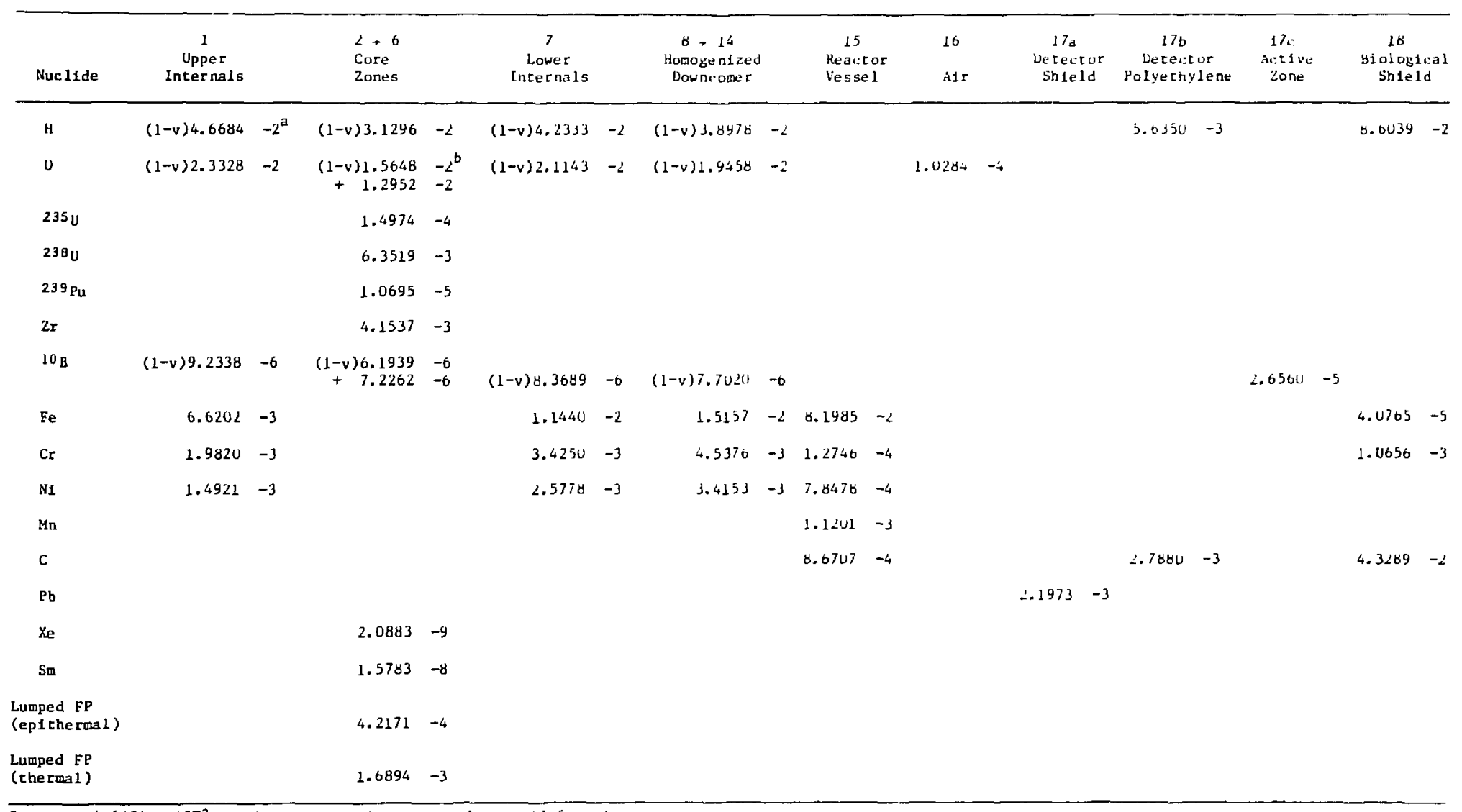

aread as $4.6684 \times 10^{-2}$, w1th $v$ reprsent 1 ng the coolant vold fraction.

bThe two components represent the coolant water and the $\mathrm{UO}_{2}$ contributions, respectively. 
resulted in the control rod material being replaced with $\sim 1000 \mathrm{ppm}$, the burnable poison represented as $\sim 440 \mathrm{ppm}$, and the soluable bor on level set at $\sim 1160 \mathrm{ppm}$ for a nonvoided coolant. The total equivalent poison is thus on the order of $2600 \mathrm{ppm}$. As voiding was modeled, the void fraction acted only upon that boron which represented the contribution from soluable bocon. Table A-4 lists the homogenized material number densities, as utilized in the calculatiunal model. They correspond directly with the region numbering in Table $A^{-1}$ and, of course, already reflect the appropriate volume fractions. 